\title{
Brain functional MRI responses to blue light stimulation in Leber's hereditary optic neuropathy
}

\author{
Stefania Evangelisti ${ }^{\text {a, } 1}$, Chiara La Morgia ${ }^{\text {b,c,1 }}$, Claudia Testa ${ }^{\text {d,* }}$, David N. Manners ${ }^{\text {a }}$, \\ Leonardo Brizi ${ }^{\mathrm{d}, \mathrm{e}}$, Claudio Bianchini ${ }^{\mathrm{a}}$, Michele Carbonelli ${ }^{\mathrm{c}}$, Piero Barboni ${ }^{\mathrm{f}}$, Alfredo A. Sadun ${ }^{\mathrm{g}}$, \\ Caterina Tonon $^{\mathrm{a}, \mathrm{h}}$, Valerio Carelli ${ }^{\mathrm{b}, \mathrm{c}, 2}$, Gilles Vandewalle ${ }^{\mathrm{i}, 2}$, Raffaele Lodi ${ }^{\mathrm{a}, \mathrm{h}, 2}$ \\ ${ }^{a}$ Unità di RM Funzionale, Dipartimento di Scienze Biomediche e Neuromotorie, Università di Bologna, Bologna, Italy \\ ${ }^{\mathrm{b}}$ Dipartimento di Scienze Biomediche e Neuromotorie, Università di Bologna, Bologna, Italy \\ ${ }^{\mathrm{c}}$ IRCCS Istituto delle Scienze Neurologiche di Bologna, UOC Clinica Neurologica, Bologna, Italy \\ d Dipartimento di Fisica ed Astronomia, Università di Bologna, Bologna, Italy \\ e Centro Fermi - Museo Storico della Fisica e Centro Studi e Ricerche «Enrico Fermi», Roma, Italy \\ ${ }^{\mathrm{f}}$ Studio Oculistico d'Azeglio, Bologna, Italy \\ ${ }^{g}$ Doheny Eye Institute, Department of Ophthalmology, David Geffen School of Medicine at University of California, Los Angeles, Los Angeles, CA, United States \\ ${ }^{\mathrm{h}}$ IRCCS Istituto delle Scienze Neurologiche di Bologna, Programma Neuroimmagini Funzionali e Molecolari, Bologna, Italy \\ ${ }^{i}$ Sleep and Chronobiology Lab, GIGA-Cyclotron Research Centre/In vivo Imaging, University of Liège, Belgium
}

\section{A R T I C L E I N F O}

\section{Keywords:}

LHON

Light stimulation

Melanopsin

fMRI

\begin{abstract}
A B S T R A C T
Melanopsin retinal ganglion cells (mRGCs) are intrinsically photosensitive photoreceptors contributing both to image and non-image-forming (NIF) functions of the eye. They convey light signal to the brain to modulate circadian entrainment, sleep, alertness, cognition, brightness perception and coarse vision. Given that rods and cones also contribute to all these impacts of light, isolating mRGC visual and NIF roles in humans is challenging so that mRGC functions remains to be fully characterized. Here, we evaluated light-driven visual and cognitive brain responses in Leber's Hereditary Optic Neuropathy (LHON), an inherited optic neuropathy that is characterized by a selective relative sparing of the melanopsin-expressing retinal ganglion cells (mRGCs). Twelve patients and twelve matched healthy controls (HC) were enrolled in a functional brain magnetic resonance imaging (fMRI) protocol including visual and visual-cognitive paradigms under blue $(480 \mathrm{~nm})$ and red $(620 \mathrm{~nm})$ light exposures. Primary visual cortex activation was detected in LHON patients; in particular higher occipital activation was found in response to sustained blue vs. red stimulation in LHON vs. HC. Similarly, brain responses to the executive task were larger under blue $v s$. red light in LHON over lateral prefrontal cortex. These findings are in line with the relative mRGC sparing demonstrated in LHON and support the mRGC contribution to both nonvisual and visual brain functions, with potential implication for visual rehabilitation in hereditary optic neuropathy patients.
\end{abstract}

\section{Introduction}

Leber's hereditary optic neuropathy (LHON, estimated prevalence: $1: 45,000)[1]$ is a maternally inherited blinding disorder due to mitochondrial dysfunction [2]. This is usually due to one of three mitochondrial DNA (mtDNA) point mutations (m.11778G $>$ A/MT-ND4, m.14484 T > C/MT-ND6, m.3460G > A/MT-ND1) that affect genes encoding complex I subunits (ND) of the respiratory chain [2]. In LHON patients, optic nerve atrophy occurs consequent to degeneration of retinal ganglion cells (RGCs) in the inner retina, whereas outer retina rods and cones are preserved. Structural MR showed microstructural alterations along the visual pathway [3-4] and grey matter loss in the visual cortex [5]. Functional MR studies are so far limited to a resting state network evaluation [6] and to a single case report in a case of Charles Bonnet syndrome in a LHON patient [7], and no extensive functional characterization of brain responses to visual stimulation has

\footnotetext{
* Corresponding author.

E-mail address: claudia.testa@unibo.it (C. Testa).

1 Contributed equally.

2 Contributed equally.
} 
A

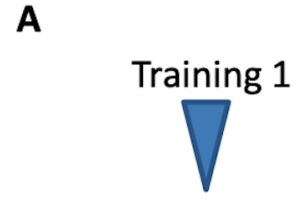

Tropicamide
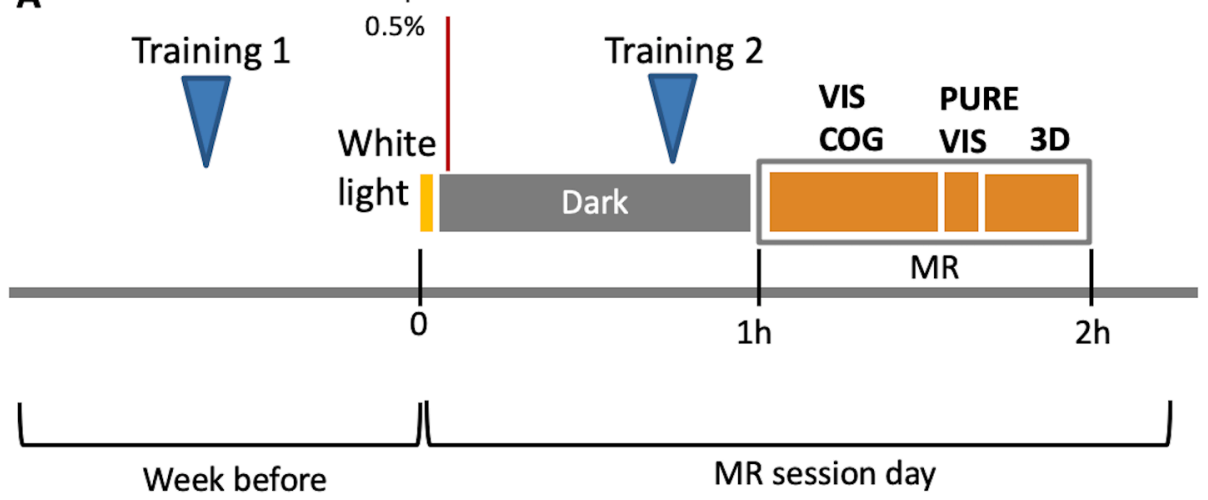

B

Pure visual paradigm

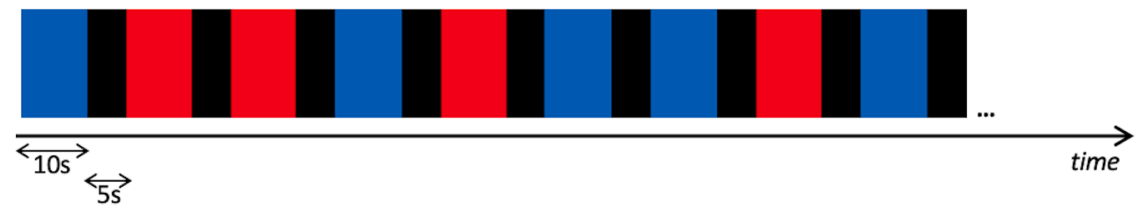

$\underline{\text { Visual cognitive paradigm }}$

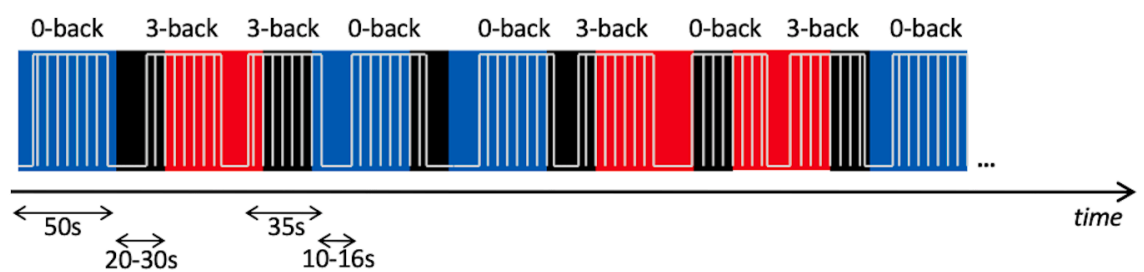

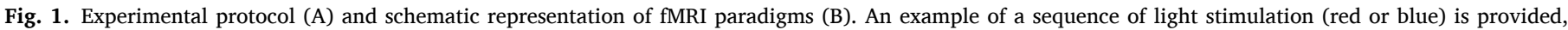

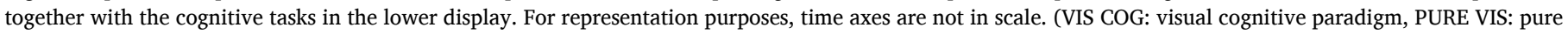
visual paradigm, 3D: volumetric structural image).

been previously reported.

In LHON, notwithstanding the generalized loss of RGCs, a subtype of RGCs expressing the photopigment melanopsin (mRGCs) is relatively spared, as demonstrated by retinal post-mortem histopathology and in vivo preservation of light-induced suppression of nocturnal melatonin secretion and pupillary light reflex (PLR) [8-11], as well as by the absence of sleep and circadian disturbances [12]. In fact, as rods and cones are the main retinal photoreceptors of the image-forming system, mRGCs, which represent about $0.5-1 \%$ of all RGCs [8,13-16], are the third class of photoreceptors in the human eye supporting mainly the non-image-forming (NIF) functions of light. These functions include circadian rhythm photoentrainment, pupillary light reflex, melatonin suppression, as well as the regulation of alertness, sleep and cognition [17-20].

Different subtypes of mRGCs exist, with slightly different functional roles, yet overall maximally sensitive to blue light $(470-480 \mathrm{~nm})$ and characterized by sustained and sluggish responses to light $[13,16,20-23]$. More recent evidences also support an involvement of mRGCs in visual processes, such as brightness detection, light adaptation, coarse image formation and spatial patterns detection [17-18,22,24-31].

From the retina, the mRGCs main central projections include the hypothalamic suprachiasmatic nucleus (SCN), site of the master circadian clock, the hypothalamic preoptic area implicated in sleep initiation, the olivary pretectal nucleus regulating pupil size, the medial amygdala, part of the olfactory and emotional response [15,32]. Furthermore, mRGCs also project to regions typically part of the visual pathway, such as the dorsal division of thalamus LGN and the midbrain superior colliculus [16] and a specific activation of the dorsal LGN has been demonstrated in mice [26,29-29,33-35].

Light stimulates cognitive brain activity $[36,37]$ and functional MRI (fMRI) studies showed that, in normally sighted individuals, light increases brain activity over the frontal eye field and inferior frontal cortex [38] and potentially in a region encompassing the suprachiasmatic nucleus [39]. Likewise, the NIF system was shown to modulate attentional, executive and emotional functions, likely through mRGCs [40] with maximal efficiency with blue light at $470-480 \mathrm{~nm}$ [19]. However, rod and cone photoreception, contribute to mRGC light responses $[19,40,41]$, making the isolation of mRGC specific roles challenging in humans [28]. Outer retina degeneration in totally blind patients has been used as a successful model to demonstrate mRGC contribution to NIF functions [17,42-44] and to evaluate the NIF impact of light on cognition $[45,46]$. Study samples were however small due to the rarity of the phenotype, making a generalization of mRGC signaling impact on cognition uncertain. In LHON, the peculiar pattern of mRGC resilience to mitochondrial dysfunction that destroys almost completely the canonical RGCs with intact outer retina, provides somehow a reverse and unique model to evaluating the light-evoked brain responses primarily mediated by mRGCs.

The aim of the present study was to investigate light impact on brain functional responses in a group of LHON patients comparing them to a cohort of healthy controls (HC), further characterizing both NIF and image-forming impacts of relatively preserved mRGC in the context of the severe optic nerve atrophy. 


\section{Materials and methods}

\subsection{Subjects}

Twelve patients with LHON and twelve age-matched controls participated to the study. Patients were consecutively recruited at the Neuro-ophthalmology Clinic, IRCCS Istituto di Scienze Neurologiche di Bologna, UOC Clinica Neurologica, Ospedale Bellaria, Italy. Healthy control subjects were recruited on a volunteer basis among Hospital and University co-workers. Local Ethical Committee approved the study (EC reference ID \#14004), according to the Declaration of Helsinki, and all the participants gave their written informed consent.

Inclusion criterion for patients was a genetically confirmed diagnosis of LHON. Exclusion criteria for both patients and HC were contraindications to MR examination, neurological or psychiatric diseases, use of drugs acting on central nervous system or on sympathetic and parasympathetic system and excessive caffeine ( $>4$ cups/day) or alcohol ( $>14$ units/week) consumption; we also excluded volunteers who were shift-workers during the previous year, or had travelled through more than one time zone during the previous 2 months. Other exclusion criteria for HC were ocular hypertension, lens opacity, retinal or optic nerve diseases including macular degeneration and colour vision abnormalities. The Morningness-eveningness questionnaire was used to assess subjects' chronotype [47]. The Pittsburgh Sleep Quality Index Questionnaire (pathological score $>5$ ) [48] and the Berlin questionnaire [49] were used to assess the presence of sleep disturbances, and the Epworth Sleepiness Scale for excessive daytime sleepiness (ESS $\geq 11$ ) [50]. Beck Anxiety Inventory [51] and 21-item Beck Depression Inventory scales [52] were used to evaluate anxiety and depression levels in the study cohort (pathological score $\geq 14$ ).

\subsection{Study design}

\subsubsection{Before fMRI sessions}

During the week preceding the fMRI session, participants were asked to follow a regular sleep schedule (maintaining their habitual sleep routine, with a tolerance interval of $1 \mathrm{~h}$ ), to be reported in sleep diaries, and they were also asked to refrain from caffeine, alcohol or other substances acting on central nervous system for 3 days before the MR session. Moreover, participants were trained to the cognitive task administered inside the MR scanner (see below; Training 1, Fig. 1-A).

\subsection{2. fMRI session}

For all participants, acquisitions were performed $4 \mathrm{~h}$ after habitual wake time. Since the seasonal variation in environmental light at the time of acquisition may affect cognitive brain activity [53], the average number of hours of light per-day at the time of MR session for each subject (data from Bologna Guglielmo Marconi Airport weather station, monthly average) was taken into account in all analyses.

On the experimental day, subjects were first exposed to white light (1000-1500 lx) for $5 \mathrm{~min}$ upon arrival, in order to standardize photic history across participants and level out this potential bias [40], and 1 or 2 drops of tropicamide $0.5 \%$ were administered to both eyes to induce mydriasis and cycloplegia.

The subjects were then blindfolded and stayed in a dark room for one hour before the fMRI acquisitions. During the dark adaption, subjects underwent a short second training to the cognitive task (Training 2, Fig. 1-A).

\subsubsection{Light exposure}

Narrow interference band-pass filters were used to produce both narrowband illuminations: blue $-480 \mathrm{~nm}$ (Full width at half maximum, FWHM $10 \mathrm{~nm}$ )- and red $-620 \mathrm{~nm}$ (FWHM: $10 \mathrm{~nm}$ ). The blue wavelength was meant to correspond to melanopsin maximal sensitivity, while the red light was equally away from the peak sensitivity of the photopic visual system (i.e. $550 \mathrm{~nm}$ ), while being close to undetected by mRGCs.
A filter wheel (AB301-T, Spectral Products, NM) was computercontrolled to switch band-pass filters and thereby change light wavelength. The light was transmitted by a metal-free purpose-built optic fibre (Fiberoptics Technology Inc, CT) from a source (DC951H illuminator, EKE lamp, Dolan-Jenner) to two small diffusers placed in front of the subjects' eyes (Ground glass diffuser 220 Grit, Thorlabs). Diffusers were designed for the purpose of this study and ensured a reasonably uniform illumination over the visual field; they were placed approximately $2 \mathrm{~cm}$ away from subjects' eyes. Irradiance could not be measured directly in the magnet, but the light source was calibrated and photon flux estimated to be $5 \times 10^{13} \mathrm{ph} \mathrm{cm}^{-2} \mathrm{~s}^{-1}$ (Power meter PM100D, Thorlabs with Silicon Power head S120VC), corresponding to an irradiance of $20.7 \mu \mathrm{W} / \mathrm{cm}^{2}$ for the blue light and $16.0 \mu \mathrm{W} / \mathrm{cm}^{2}$ for the $620 \mathrm{~nm}$ red light

On the lux scale, to quantify the effective illuminance for human photopigments following the International Standard CIE S026:2018 [54], for a wavelength of $480 \mathrm{~nm}$ and an irradiance of $20.7 \mu \mathrm{W} / \mathrm{cm}^{2}$ we obtained the following values: photopic illuminance $=19.80 \mathrm{~lx}$, melanopic illuminance $(\mathrm{mRGCs})=151.81 \mathrm{~lx}$, rhodopic illuminance $($ rods $)=114.05 \mathrm{~lx}$, cyanopic illuminance $(\mathrm{S}$-cones $)=89.32 \mathrm{~lx}$, chloropic illuminance $(\mathrm{M}$-cones $)=50.85 \mathrm{~lx}$, erythropic illuminance $(\mathrm{L}-$ cones) $=26.62 \mathrm{~lx}$. For a wavelength of $620 \mathrm{~nm}$ and an irradiance of $16.0 \mu \mathrm{W} / \mathrm{cm}^{2}$ we instead obtained: photopic illuminance $=33.831 \mathrm{x}$, melanopic illuminance $(\mathrm{mRGCs})=0.09 \mathrm{~lx}$, rhodopic illuminance (rods) $=0.66 \mathrm{~lx}$, cyanopic illuminance (S-cones) $=0 \mathrm{~lx}$; chloropic illuminance $\quad(\mathrm{M}$-cones $)=9.34 \mathrm{~lx}$, erythropic illuminance (Lcones) $=41.301 \mathrm{x}$.

The light device produced no perceptible sounds or temperature change. The total amount of blue light received during the experiment was 4 orders of magnitude below the blue-light hazard threshold as defined by the International Commission on Non-Ionizing Radiation Protection (ICNIRP Guidelines 2013) [55].

\subsection{4. fMRI paradigms}

The first paradigm tested was meant to investigate the possible role of mRGCs in a pure visual setting. Participants were exposed to blue or red lights for periods of $10 \mathrm{~s}$ separated with $5 \mathrm{~s}$ of complete darkness $(<0.01 \mathrm{~lx})$, with a random colour alternation, for a total duration of 5 min (Fig. 1-B).

In order to investigate mRGC-driven modulation of brain responses during a working memory task, a cognitive paradigm was constructed based on previous studies [45,56] (Fig. 1-B). The paradigm included $50 \mathrm{~s}$ illumination periods under blue or red light exposure, separated by dark periods of 20 to $30 \mathrm{~s}$ (mean $25 \mathrm{~s}$ ). While exposed to light or maintained in darkness, participants performed $35 \mathrm{~s}$ blocks of either 0-back and 3back auditory task separated by rest periods lasting 10 to $16 \mathrm{~s}$ (mean $13 \mathrm{~s}$ ). Both auditory tasks consisted in series of consonants. The 0-back task was a simple letter detection task during which subjects were requested to state whether or not the consonant was an "r". The 3-back task is a working memory task requesting to state whether each consonant was identical to the consonant presented three stimuli earlier. It is an executive task probing maintenance and updating of information as well as attention and auditory processing $[57,58]$.

Responses were given by pressing a button on a MR-compatible handgrip when the answer was yes. Stimuli consisted of nine Italian monosyllabic consonants (duration $=0.5 \mathrm{~s}$, Inter-Stimulus Inter$\mathrm{val}=2 \mathrm{~s}$ ), produced using COGENT 2000 (www.vislab.ucl.ac.uk/c ogent.php), implemented in MATLAB (MathWorks, MA), and transmitted to the participants using MR compatible headphones. Series of stimuli were constructed with $30 \%$ hits so that the difficulty level was similar in all blocks, were presented only once and were randomly assigned to a task block. Each auditory task block consisted of a series of 14 consonants. A total of 42 blocks were presented, 21 of 0-back and 21 of 3-back, randomly alternated. Each type of task was preceded by a short vocal instruction. The cognitive task was totally uncorrelated to the light condition, i.e. presentation of task blocks was independent 
from light changes, so that both the impact of light on prefrontal cognitive brain activity and occipital visual brain activity could be investigated separately. The duration of the cognitive paradigm was about $35 \mathrm{~min}$.

\section{3. $f M R I$ acquisition}

fMRI acquisitions were performed with a $1.5 \mathrm{~T}$ system (GE Medical System Signa HDx 15), equipped with an 8-channel brain phased array coil. The static magnetic field of the apparatus was therefore lower than previous 3 T fMRI studies on the NIF impact of light [45,56,59]. Since signal and signal-to-noise ratio (SNR) decrease non-linearly as a function of magnetic field, this implies that sensitivity of the apparatus was much lower than previously. Yet, the excellent access to the rare phenotype of interest at the University of Bologna, i.e. relative increase in mRGC photoreception in LHON patient, led us to postulate that the most prominent effects, i.e. the greater relative difference in mRGC/RGC output, would be detectable with the $1.5 \mathrm{~T}$ apparatus. Functional MR images were acquired with a multislice $\mathrm{T} 2 *$-weighted gradient-echoplanar sequence using pure axial slice orientation (34 slices, thickness $4 \mathrm{~mm}$, in-plane resolution $1.875 \times 1.875 \mathrm{~mm}$, field of view FOV $=240 \times 240 \mathrm{~mm}$, matrix size $=98 \times 98 \times 34$, repetition time $\mathrm{TR}=3000 \mathrm{~ms}$, echo time $\mathrm{TE}=40 \mathrm{~ms}$, flip angle $=90^{\circ}$ ). High-resolution volumetric structural images were acquired using a T1-weighted fast spoiled gradient echo (FSPGR) sequence, $(\mathrm{TR}=12.4 \mathrm{~ms}, \mathrm{TE}=5.2 \mathrm{~ms}$, inversion time $\mathrm{TI}=600 \mathrm{~ms}$, flip angle $=10^{\circ}$, matrix size $=256 \times 256 \mathrm{~mm}$, FOV $=256 \times 256 \mathrm{~mm}$, voxel size $1 \times 1 \times 1 \mathrm{~mm}$ ). Acquisitions started with the visual cognitive paradigm, then the pure visual paradigm followed, and the structural images acquisitions.

\section{4. fMRI data analysis}

Analyses of fMRI data were performed with the FSL software (htt ps://fsl.fmrib.ox.ac.uk/fsl/). Image pre-processing included motion correction through rigid body registration (MCFLIRT, Motion Correction FMRIB's Linear Image Registration Tool), high-pass filtering (cut-off $100 \mathrm{~s}$ for pure visual paradigm and $150 \mathrm{~s}$ for visual-cognitive paradigm), spatial smoothing (gaussian kernel FWHM $5 \mathrm{~mm}$ ) and slice timing correction.

At the single subject level, changes in brain responses were estimated by using a general linear model, in which aspects of interest were modelled using boxcar or stick functions convolved with a doublegamma hemodynamic response function. In particular, for the pure visual paradigm, the following explanatory variables (EV) were included

Table 1

Sample demographics and questionnaire on sleep, anxiety and depression. (LHON: Leber's hereditary optic neuropathy; HC: healthy controls; PSQUI: Pittsburgh Sleep Quality Index; ESS: Epworth Sleepiness Scale; OSA: Obstructive sleep apnea; $\mathrm{p}$-value $t$-test unless differently specified).

\begin{tabular}{|c|c|c|c|}
\hline & LHON & $\mathrm{HC}$ & p-value \\
\hline $\begin{array}{l}\text { Age } \\
\qquad(\text { mean } \pm \text { sd) years }\end{array}$ & $38.2 \pm 12.9$ & $37.8 \pm 13.7$ & 0.95 \\
\hline $\begin{array}{r}\text { Gender } \\
(\mathrm{M} / \mathrm{F})\end{array}$ & $10 / 2$ & $8 / 4$ & $\begin{array}{l}0.35 \\
\text { (Pearson's } \chi^{2} \text { ) }\end{array}$ \\
\hline $\begin{array}{l}\text { Average hours of light } \\
\quad(\text { mean } \pm \mathrm{sd})\end{array}$ & $12.6 \pm 2.1$ & $12.7 \pm 2.2$ & 0.95 \\
\hline $\begin{array}{l}\text { Extreme morning chronotype } \\
\quad(\text { mean } \pm \mathrm{sd})\end{array}$ & $59.8 \pm 9.3$ & $57.4 \pm 5.0$ & 0.44 \\
\hline $\begin{array}{l}\text { PSQI } \\
\quad(\text { mean } \pm \text { sd })\end{array}$ & $4.9 \pm 2.3$ & $3.7 \pm 2.2$ & 0.22 \\
\hline $\begin{array}{l}\text { ESS } \\
\qquad(\text { mean } \pm \text { sd })\end{array}$ & $6.8 \pm 3.8$ & $7.3 \pm 1.4$ & 0.65 \\
\hline Berlin questionnaires for OSA & Low risk & Low risk & / \\
\hline $\begin{array}{l}\text { Beck anxiey } \\
\quad(\text { mean } \pm \mathrm{sd})\end{array}$ & $12.6 \pm 7.7$ & $5.4 \pm 6.8$ & 0.05 \\
\hline $\begin{array}{l}\text { Beck depression } \\
\quad(\text { mean } \pm \mathrm{sd})\end{array}$ & $7.2 \pm 6.5$ & $5.9 \pm 2.9$ & 0.55 \\
\hline
\end{tabular}

in the design matrix: blue and red (modelled with boxcar functions), blue on, blue off, red on and red off (modelled with stick functions). Movement parameters derived from realignment for motion correction were added as covariate of no interest. COPE (Contrast of Parameter Estimates) maps were generated for the following contrasts: blue, red, blue $>$ red, blue $<$ red, blue on, red on, blue on $>$ red on, blue on $<$ red on. Light offsets were included as regressors of no interest.

Regarding the visual cognitive paradigm, boxcar functions were used to model 0-back task blocks, 3-back task blocks, blue illumination periods and red illumination periods. Stick functions were used for light onset and offset which were considered as covariate of no interest together with movement parameters. The following EVs were included in the design matrix: 0-back, 3-back, blue, red (modelled with boxcar functions), blue on, blue off, red on, red off (modelled with stick functions), and then the interactions between light and task: 0-back under blue, 0-back under red, 3-back under blue, 3-back under red. In all contrasts, executive brain responses were isolated by subtracting brain responses to the 0-back task from the brain responses to the 3back task. We assessed these brain responses irrespective of the light condition and then evaluated the impact of light on executive responses. COPE maps were generated for the following contrasts: 3 -back $>0$-back, blue, red, blue $>$ red, blue $<$ red, [(3-back blue -0 -back blue) $>$ (3-back red -0 back red)], [(3-back blue - 0-back blue) < (3-back red - 0-back red)].

Functional images were linearly aligned to structural images and structural images were non-linearly aligned to the MNI template. At the group level, comparisons between LHON patients and HC were carried out with non-parametric statistics obtained by permutation methods (FSL randomise, with 5000 permutations). Age, sex and the average numbers of hours of light per day at the moment of MRI acquisitions were added as covariate of no interest. Comparisons were performed within pre-defined regions of interests: primary visual cortex for the visual effects and prefrontal brain regions associated with working memory tasks for the visual-cognitive effect. Precisely, V1 was defined based on Juelich histological atlas [60] definition at $25 \%$ probability, while regions involved in working memory task were defined according to a recent meta-analysis results [61] by drawing a sphere of $10 \mathrm{~mm}$ radius around each coordinate reported for all active main effect and load condition. Statistical inferences were made from statistical maps that were corrected for multiple comparisons with a threshold free cluster enhancement (TFCE) method, considering significant results at $\mathrm{p}<0.05$. An analogous approach was used to investigate possible correlations between fMRI results and patients' ophthalmological data. Input data for the statistical analysis of this study, including fMRI COPE images and task performances, are available at Mendeley Data (https:// doi.org/10.17632/xjj2vpbsck.1).

\subsection{Demographic and behavioural data analysis}

Normal distribution of all data types was checked with a ShapiroWilk test. Gender was compared between the two groups with Pearson's $\chi^{2}$ test, while age and the average hours of light were compared with a $t$-test. The performances in the two training sessions of the $n$-back cognitive tasks were compared between sessions with a paired $t$-test, and between patients and controls with a $t$-test. As for the performance of the cognitive task during MR acquisitions, a two-way mixed design ANOVA was performed, with group (patients or controls) as independent factor and light conditions (blue, red, darkness) as the three-level repeated measures.

\subsection{Ophthalmological evaluations}

Both patients and controls performed an ophthalmological evaluation which included the assessment of visual acuity (ETDRS chart), measurement of intraocular pressure (IOP), evaluation of the anterior chamber by means of slit lamp and of the fundus oculi by means of direct ophthalmoscopy. Moreover, participants performed evaluation of colour 


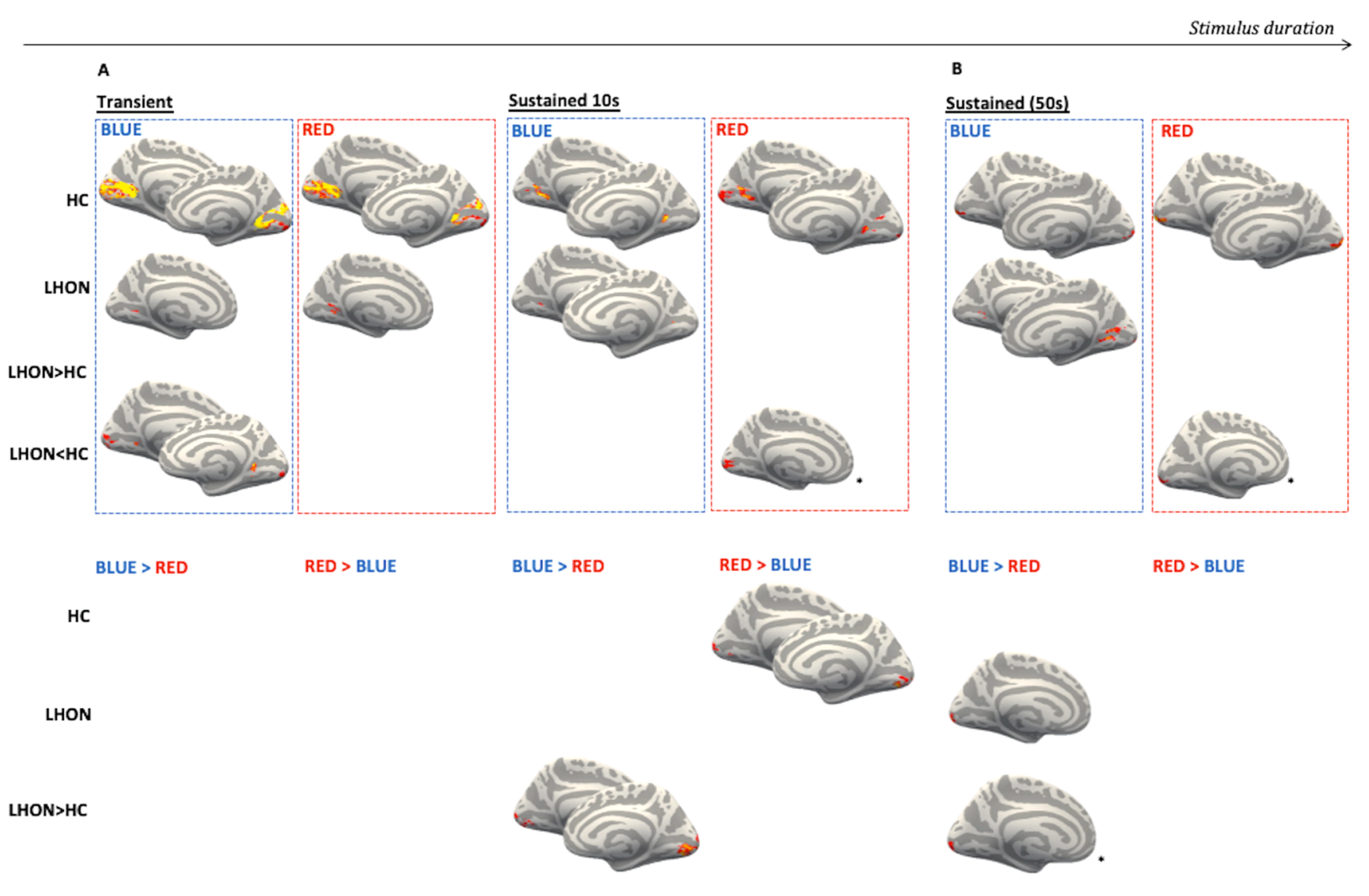

LHON<HC

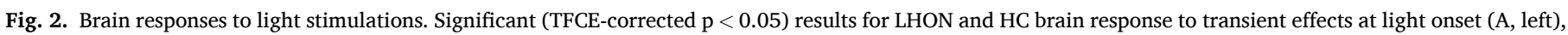

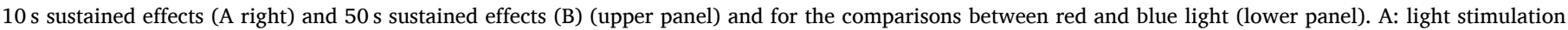

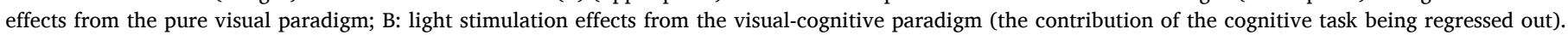

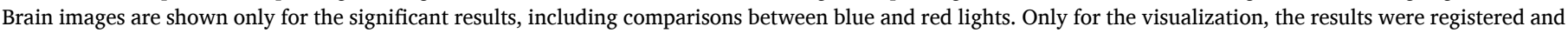

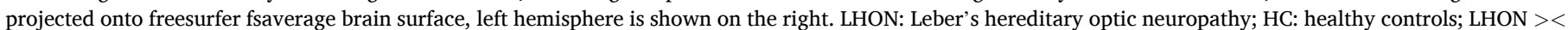

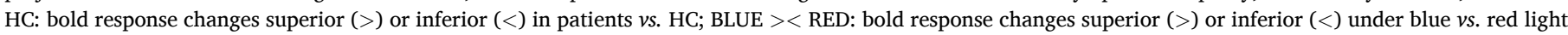
exposure *: only for visualization purposes clusters are shown at $\mathrm{p}<0.1$ (clusters were however found at $\mathrm{p}<0.05$, see Table 2 ).

vision (Ishihara's Test for Colour-Blindness-Kanehara Shupman Co., Tokyo, Japan), computerized visual field (Humphrey, Zeiss) and optical coherence tomography (OCT) (Stratus, Zeiss). For correlation analysis the following metrics were used: visual acuity, mean deviation for computerized visual fields, retinal nerve fibre layer (RNFL) thickness average and single quadrants (temporal, superior, nasal and inferior) thickness (for more details on OCT methods see [62].

\section{Results}

\subsection{Demographic, clinical and behavioral results}

LHON patients and HC did not significantly differ in terms of age, gender and average number of hours of light at the time of fMRI acquisitions. None of the participants had an extreme morning-evening chronotype, nor presented excessive sleep-wake disturbances, as evaluated by PSQI, ESS and Berlin questionnaires. Beck anxiety and depression scores were normal in all participants, except for two patients who presented mild to moderate levels of anxiety and depression (Table 1).

Sample demographic are reported and compared in Table 1. Full ophthalmological description of patients is reported in Table 4. Participant were trained twice to the MRI task prior to entering the MR apparatus. At the second training session performed $1 \mathrm{~h}$ prior MRI acquisition, all the participants reached at least $75 \%$ of accuracy in both n-back tasks. Over the whole study cohort, there was a modest but significant improvement of performances between the first training (during the week before MRI acquisitions) and the second one (just before MRI acquisitions) in the 3-back task (paired $t$-test, $\mathrm{p}=0.020$, mean first training: $85.7 \%$, mean second training: $89.3 \%$ ).

As for the accuracy to n-back tasks during fMRI acquisition, as intended given the short block duration of both task and light exposures, there was no significant main effect of group (0-back: $F=0.552$, $\mathrm{p}=0.473$; 3-back: $\mathrm{F}=0.759, \mathrm{p}=0.402$ ), nor light condition (0-back: $\mathrm{F}=2.861, \mathrm{p}=0.113$; 3-back: $\mathrm{F}=3.732, \mathrm{p}=0.056$ ), as well as no significant interaction between group and light condition (0-back: $\mathrm{F}=1.379, \mathrm{p}=0.272 ; 3$-back: $\mathrm{F}=1.932, \mathrm{p}=0.174)$. These results imply that the fMRI results were not biased by significant differences in the cognitive task performances.

\subsection{Narrowband light stimulations}

We first considered the impact of light exposure only, i.e. independent of the presence of a cognitive task. Brain responses to narrowband light stimulation were considered for three different durations of light stimuli: transient effects (light onset) and $10 \mathrm{~s}$, during the pure visual paradigm, and $50 \mathrm{~s}$ sustained effects during the visual-cognitive paradigm. 
Transient blue light, $\mathrm{LHON}<H C$ Intracalcarine Cortex (r)

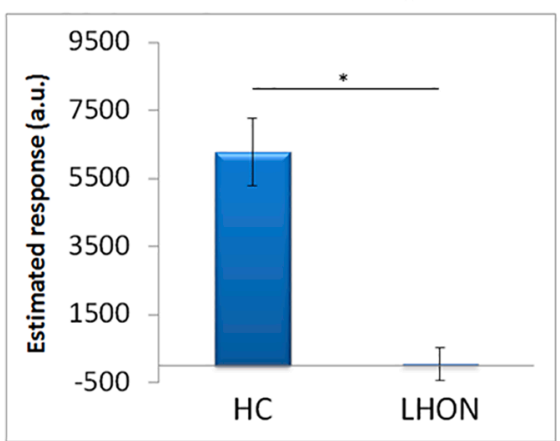

Sustained (10s) red light, $L H O N<H C$ Intracalcarine Cortex ( $r)$

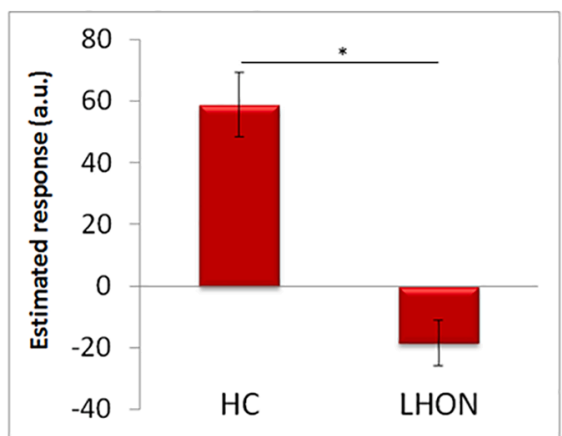

Sustained (10s) blue > red, LHON > HC Intracalcarine Cortex (I)

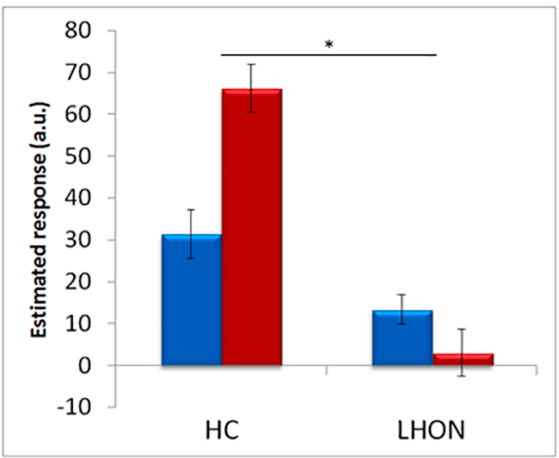

Sustained (10s) red > blue, HC Occipital Pole (I)

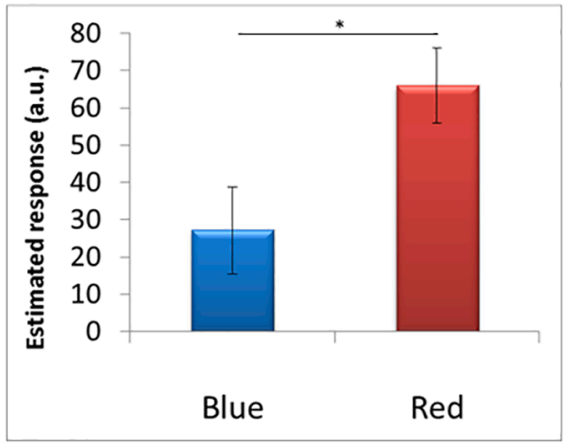

Sustained (50s) red light, $L H O N<H C$ Occipital Pole (I)

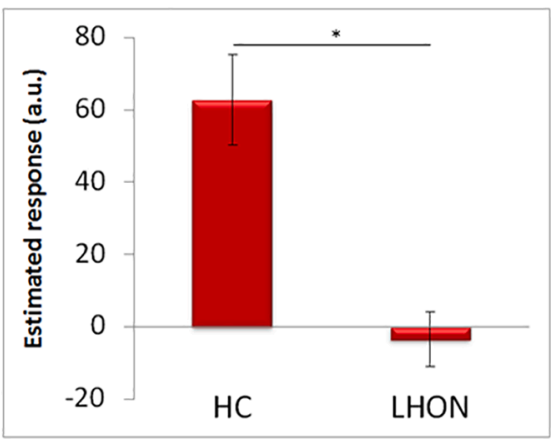

Sustained (50s) blue > red, LHON occipital Pole ( $r$ )

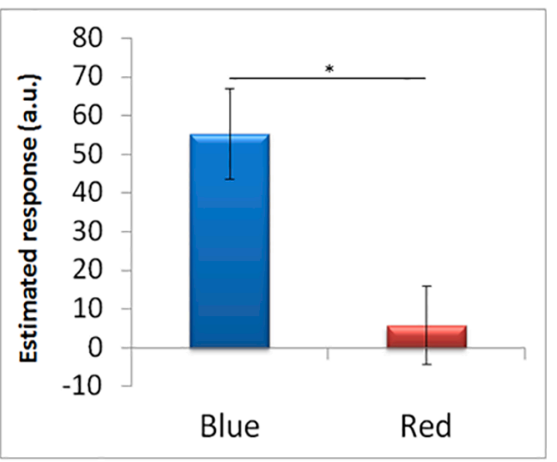

Sustained (50s) blue > red, $\mathrm{LHON}>\mathrm{HC}$ Occipital Pole ( $r$ )

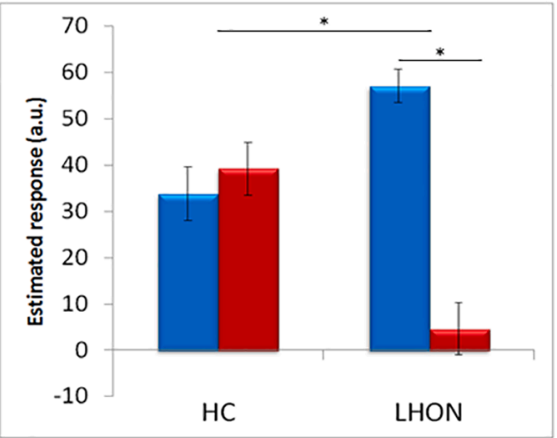

Fig. 3. Bar plot of brain responses to light stimulations. Bar plots describing the mean parameters estimates (average in arbitrary units \pm standard error of the mean) of the significant voxels that were found for the comparisons between light conditions and/or groups (Fig. 2, Table 3). A representative brain response, taken from the main significant cluster, is displayed for each contrast yielding a significant difference (indicated with *).

At light onset, activations of the primary visual cortex were detected in both groups for both light conditions, but with a greater extent in HC. Significantly higher response was detected in HC compared to LHON patients under blue light. No significant differences were detected when blue and red light were compared in either groups, and no significant difference in blue $v s$. red light were detected across groups (Figs. 2 and 3, Table 2).

Both groups showed sustained responses to $10 \mathrm{~s}$ and $50 \mathrm{~s}$ exposure to blue light over several parts of the primary visual cortex. In contrast, sustained visual cortex responses to $10 \mathrm{~s}$ and $50 \mathrm{~s}$ red light exposure were only detected in HC. Accordingly, sustained responses to both 10 and $50 \mathrm{~s}$ red light were significantly higher in HC than in LHON patients.

When assessing the interaction between light conditions and groups, sustained responses were greater under blue $v$ s. red light exposure in LHON patients relative to $\mathrm{HC}$ in the occipital cortex for both 10 and $50 \mathrm{~s}$ conditions (Figs. 2 and 3, Table 2).

No significant correlations were found in LHON patients between functional visual responses under either blue or red light and ophthalmological data, namely visual acuity, visual fields and retinal nerve fibre layer thickness.

\subsection{Light modulation of cognitive brain responses}

Executive brain responses, isolated by subtracting 0-back brain responses from 3-back responses, were observed in the typical brain areas sustaining working memory [58] and similar between the two groups, 
Table 2

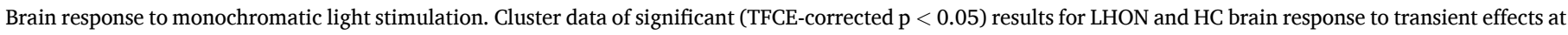

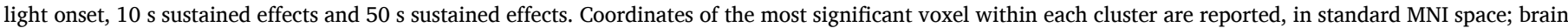

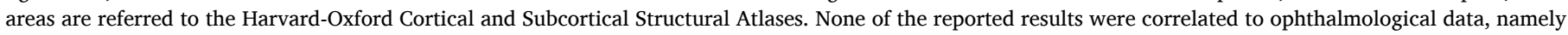
visual acuity, visual fields and retinal nerve fiber layer thickness. (LHON: Leber's hereditary optic neuropathy; HC: healthy controls; l: left; r: right.)

\begin{tabular}{|c|c|c|c|c|c|c|c|}
\hline & & \multirow[t]{2}{*}{ Volume $\left(\mathrm{mm}^{3}\right)$} & \multirow[t]{2}{*}{ p-value } & \multicolumn{3}{|c|}{ Coordinates (mm) } & \multirow[t]{2}{*}{ Area (side) } \\
\hline & & & & $\mathrm{x}$ & $\mathrm{y}$ & $\mathrm{z}$ & \\
\hline \multicolumn{8}{|c|}{ Transient effects } \\
\hline \multirow[t]{7}{*}{ Blue } & HC & 16840 & $<\mathrm{E}-10$ & -18 & -52 & -4 & Lingual Gyrus (1) \\
\hline & LHON & 216 & $1.80 \mathrm{E}-02$ & 22 & -58 & 4 & Lingual Gyrus (r) \\
\hline & LHON > HC & no significant voxels & & & & & \\
\hline & LHON $<$ HC & 1312 & $2.00 \mathrm{E}-02$ & 14 & -84 & 14 & Intracalcarine Cortex (r) \\
\hline & & 640 & $2.80 \mathrm{E}-02$ & -4 & -94 & -10 & Occipital Pole (l) \\
\hline & & 456 & $5.00 \mathrm{E}-03$ & -22 & -52 & 2 & Lingual Gyrus (1) \\
\hline & & 264 & $1.70 \mathrm{E}-02$ & 20 & -54 & 0 & Lingual Gyrus (r) \\
\hline \multirow[t]{4}{*}{ Red } & HC & 11664 & $1.00 \mathrm{E}-03$ & 20 & -54 & 0 & Lingual Gyrus (r) \\
\hline & LHON & 712 & $1.70 \mathrm{E}-02$ & 22 & -58 & 6 & Intracalcarine Cortex (r) \\
\hline & LHON > HC & no significant voxels & & & & & \\
\hline & LHON $<$ HC & no significant voxels & & & & & \\
\hline \multirow[t]{4}{*}{ Blue $>$ Red } & $\mathrm{HC}$ & no significant voxels & & & & & \\
\hline & LHON & no significant voxels & & & & & \\
\hline & LHON > HC & no significant voxels & & & & & \\
\hline & LHON $<$ HC & no significant voxels & & & & & \\
\hline \multirow[t]{4}{*}{ Blue $<$ Red } & HC & no significant voxels & & & & & \\
\hline & LHON & no significant voxels & & & & & \\
\hline & LHON > HC & no significant voxels & & & & & \\
\hline & LHON < HC & no significant voxels & & & & & \\
\hline \multicolumn{8}{|c|}{ Sustained effects (10 $s$ ) } \\
\hline Blue & HC & 1792 & $3.00 \mathrm{E}-03$ & 18 & -64 & 2 & Intracalcarine Cortex (r) \\
\hline & & 440 & 4.00E-03 & -20 & -56 & 0 & Lingual Gyrus (1) \\
\hline & LHON & 136 & $3.70 \mathrm{E}-02$ & 18 & -60 & 2 & Lingual Gyrus (r) \\
\hline & & 40 & $1.40 \mathrm{E}-02$ & -18 & -66 & 4 & Intracalcarine Cortex (1) \\
\hline & LHON > HC & no significant voxels & & & & & \\
\hline & LHON $<$ HC & no significant voxels & & & & & \\
\hline Red & $\mathrm{HC}$ & 4240 & $6.00 \mathrm{E}-03$ & 20 & -62 & 8 & Intracalcarine Cortex (r) \\
\hline & & 984 & $2.60 \mathrm{E}-02$ & -14 & -100 & -10 & Occipital Pole (1) \\
\hline & & 344 & $1.40 \mathrm{E}-02$ & -22 & -56 & 0 & Lingual Gyrus (1) \\
\hline & & 336 & $2.20 \mathrm{E}-02$ & -18 & -66 & 12 & Supracalcarine cortex (l) \\
\hline & LHON & no significant voxels & & & & & \\
\hline & LHON > HC & no significant voxels & & & & & \\
\hline & LHON $<$ HC & 16 & $4.70 \mathrm{E}-02$ & 20 & -80 & 12 & Intracalcarine Cortex (r) \\
\hline & & 16 & $4.80 \mathrm{E}-02$ & 16 & -98 & 0 & Occipital Pole (r) \\
\hline Blue $>$ Red & HC & no significant voxels & & & & & \\
\hline & LHON & no significant voxels & & & & & \\
\hline & LHON > HC & 5400 & $7.00 \mathrm{E}-03$ & -6 & -88 & -2 & Intracalcarine Cortex (l) \\
\hline & & 968 & $2.30 \mathrm{E}-02$ & 20 & -94 & 10 & Occipital Pole (r) \\
\hline & & 24 & 4.40E-02 & 20 & -86 & -4 & Occipital Fusiform Gyrus (r) \\
\hline & LHON $<$ HC & no significant voxels & & & & & \\
\hline Red $>$ Blue & $\mathrm{HC}$ & 2512 & $4.00 \mathrm{E}-03$ & -14 & -96 & 0 & Occipital Pole (1) \\
\hline & & 1072 & $1.00 \mathrm{E}-02$ & 18 & -94 & 8 & Occipital Pole (r) \\
\hline & & 208 & $4.20 \mathrm{E}-02$ & 8 & -78 & -6 & Lingual Gyrus (r) \\
\hline & & 144 & $2.30 \mathrm{E}-02$ & 20 & -86 & -4 & Occipital Fusiform Gyrus (r) \\
\hline & & 112 & $4.20 \mathrm{E}-02$ & 14 & -100 & 2 & Occipital Pole (r) \\
\hline & LHON & no significant voxels & & & & & \\
\hline & LHON > HC & no significant voxels & & & & & \\
\hline & LHON $<$ HC & no significant voxels & & & & & \\
\hline Sustained eff & & & & & & & \\
\hline Blue & HC & 2600 & $7.00 \mathrm{E}-03$ & -14 & -100 & -6 & Occipital Pole (1) \\
\hline & LHON & 2160 & $8.00 \mathrm{E}-03$ & 20 & -62 & 4 & Intracalcarine Cortex (r) \\
\hline & & 1152 & $3.20 \mathrm{E}-02$ & 16 & -96 & -8 & Occipital Pole (r) \\
\hline & & 296 & $2.90 \mathrm{E}-02$ & 4 & -92 & -6 & Occipital Pole (r) \\
\hline & & 200 & $3.90 \mathrm{E}-02$ & -14 & -104 & -12 & Occipital Pole (l) \\
\hline & & 168 & 4.30E-02 & -20 & -60 & 4 & Intracalcarine Cortex (1) \\
\hline & & 144 & 4.50E-02 & -28 & -100 & 0 & Occipital Pole (1) \\
\hline & & 56 & 4.60E-02 & 4 & -84 & -8 & Lingual Gyrus (r) \\
\hline & & 16 & $4.90 \mathrm{E}-02$ & 18 & -102 & 8 & Occipital Pole (r) \\
\hline & LHON > HC & no significant voxels & & & & & \\
\hline & LHON $<$ HC & no significant voxels & & & & & \\
\hline Red & $\mathrm{HC}$ & 6080 & $1.00 \mathrm{E}-03$ & -14 & -100 & -6 & Occipital Pole (l) \\
\hline & LHON & no significant voxels & & & & & \\
\hline & LHON > HC & no significant voxels & & & & & \\
\hline & LHON $<$ HC & 32 & $3.40 \mathrm{E}-02$ & -18 & -96 & -12 & Occipital Pole (1) \\
\hline Blue $>$ Red & $\mathrm{HC}$ & no significant voxels & & & & & \\
\hline & LHON & 1464 & $1.00 \mathrm{E}-02$ & 18 & -96 & -8 & Occipital Pole (r) \\
\hline & & 32 & $4.30 \mathrm{E}-02$ & 14 & -90 & 16 & Occipital Pole (r) \\
\hline
\end{tabular}




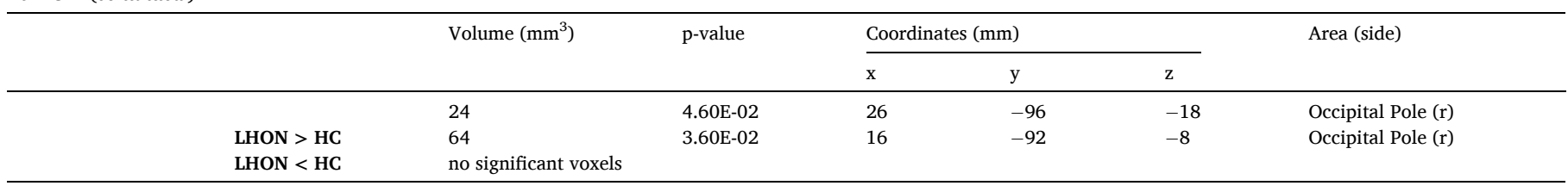

\section{3-back > 0-back}

HC

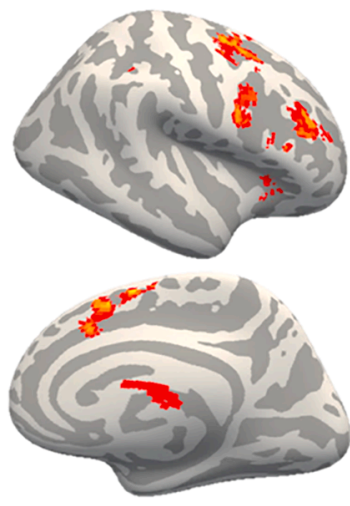

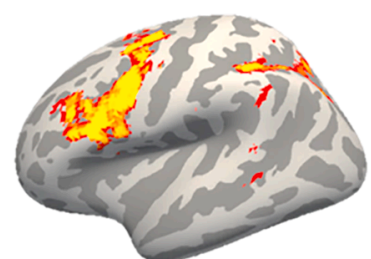

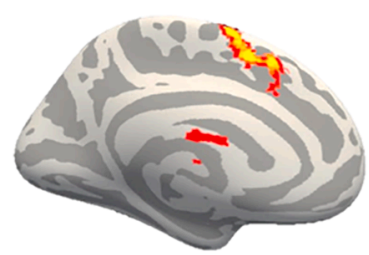

\section{LHON}
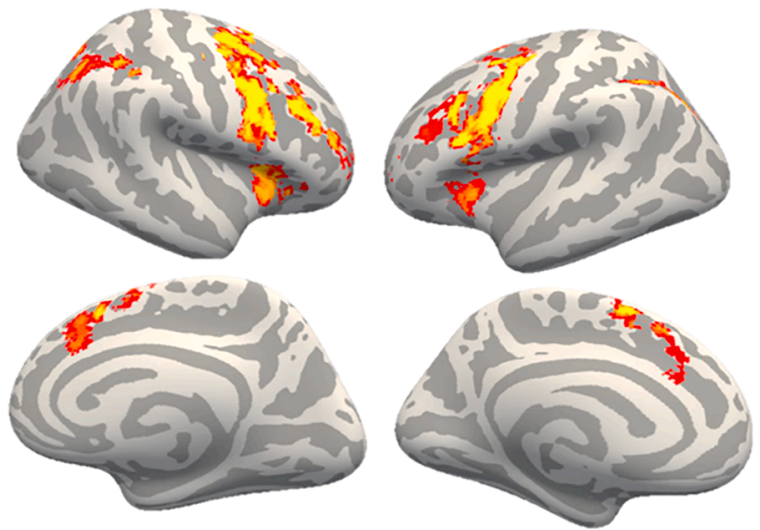

0

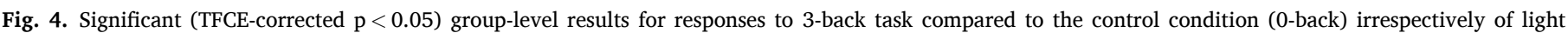

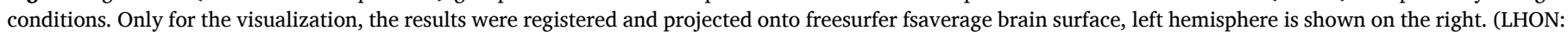
Leber's hereditary optic neuropathy; HC: healthy controls.)

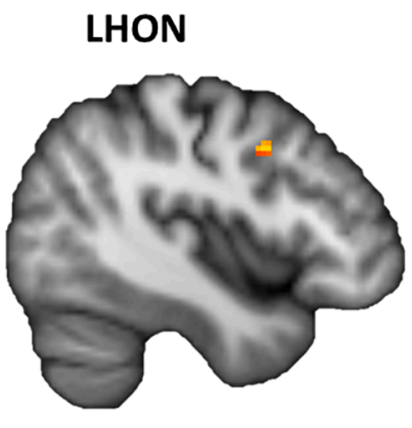

$x=-43$

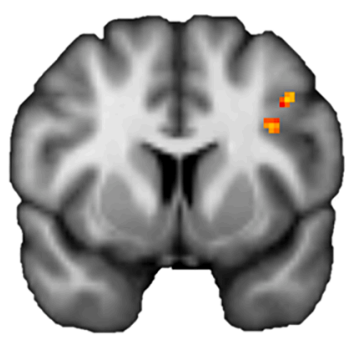

$y=7$

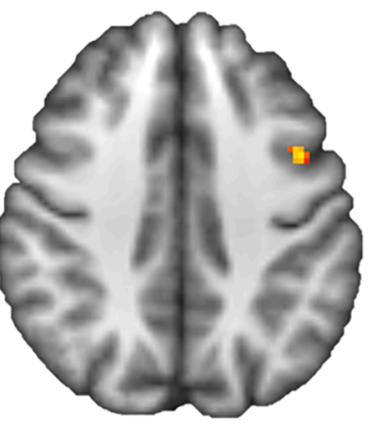

$z=40$

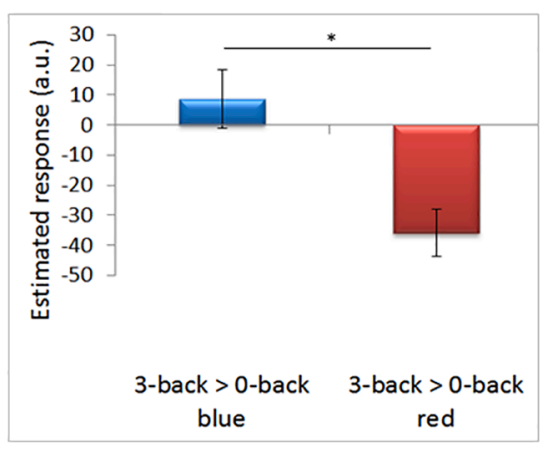

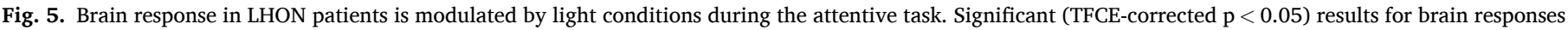

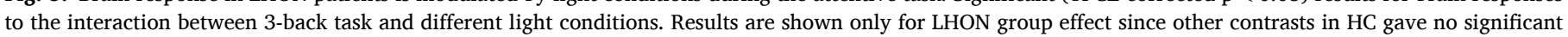

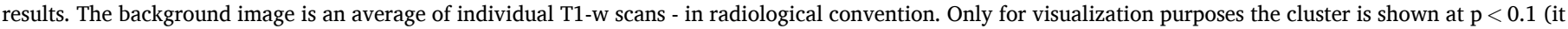

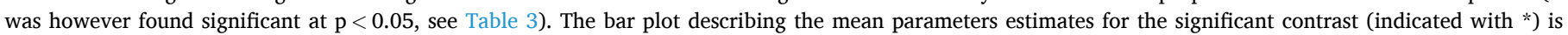
reported in the lateral panel.

and encompassed the prefrontal, parietal and cingulate cortices, thalamus, and putamen (Fig. 4; Table 5). No group differences were detected suggesting that both patients and HC successfully and similarly performed both auditory tasks.

We then examined whether executive brain responses were affected in a wavelength-dependent manner. Analyses reveal that, compared to red light exposure, blue light exposures increased executive brain responses in LHON patients in the middle frontal gyrus (Fig. 5, Table 3). No such a significant difference was detected in HC and groups did not significantly differ when considering the differential impact of light wavelength on executive responses.
In addition, no significant correlations were found in LHON patients between functional brain cognitive responses under either blue or red light and ophthalmological data, namely visual acuity, visual fields and retinal nerve fiber layer thickness.

\section{Discussion}

This study investigated the light-driven modulation of brain activity through fMRI in a cohort of chronically and severely affected LHON patients, large enough to allow for group level statistical inferences. The results demonstrate that primary visual cortex of LHON patients was 
Table 3

Executive brain response in LHON patients is modulated by light conditions. Cluster data for the significant (TFCE-corrected $\mathrm{p}<0.05$ ) results for brain responses to the interaction between 3-back task and different light conditions. Coordinates of the most significant voxel within each cluster are reported, in standard MNI space; brain areas are referred to the Harvard-Oxford Cortical and Subcortical Structural Atlases. None of the reported results were correlated to ophthalmological data, namely visual acuity, visual fields and retinal nerve fiber layer thickness. (LHON: Leber's hereditary optic neuropathy; HC: healthy controls; l: left; r: right.).

\begin{tabular}{|c|c|c|c|c|c|c|}
\hline & \multirow[t]{2}{*}{ Volume $\left(\mathrm{mm}^{3}\right)$} & \multirow[t]{2}{*}{ p-value } & \multicolumn{3}{|c|}{$\begin{array}{l}\text { Coordinates } \\
(\mathrm{mm})\end{array}$} & \multirow[t]{2}{*}{ Area } \\
\hline & & & $\mathrm{x}$ & $\mathrm{y}$ & $\mathrm{z}$ & \\
\hline \multicolumn{7}{|c|}{$(3-b a c k>0 \text {-back })_{\text {blue }}>(3-b a c k>0 \text {-back })_{\text {red }}$} \\
\hline LHON & 24 & $4.10 \mathrm{E}-02$ & -44 & 6 & 40 & $\begin{array}{l}\text { Middle Frontal } \\
\text { Gyrus (1) }\end{array}$ \\
\hline $\mathrm{HC}$ & \multicolumn{6}{|c|}{ no significant voxels } \\
\hline LHON > HC & \multicolumn{6}{|c|}{ no significant voxels } \\
\hline LHON $<$ HC & \multicolumn{6}{|c|}{ no significant voxels } \\
\hline \multicolumn{7}{|c|}{$(3-b a c k>0 \text {-back })_{\text {blue }}<(3-b a c k>0 \text {-back })_{\text {red }}$} \\
\hline LHON & \multicolumn{6}{|c|}{ no significant voxels } \\
\hline HC & \multicolumn{6}{|c|}{ no significant voxels } \\
\hline LHON > HC & \multicolumn{6}{|c|}{ no significant voxels } \\
\hline LHON $<$ HC & \multicolumn{6}{|c|}{ no significant voxels } \\
\hline
\end{tabular}

active in response to, monochromatic blue light stimuli of different durations (transient, sustained $10 \mathrm{~s}$ and $50 \mathrm{~s}$ ), with a significantly higher sustained activation in response to blue compared to red light stimulation in LHON compared to HC. In particular, we found V1 cortex activation with both blue and red light at all stimuli durations in $\mathrm{HC}$ subjects, whereas for LHON V1 activation was evident only in response to blue light. It appears therefore that our findings arise from a greater relative difference between light conditions (blue $v s$. red) in LHON patients compared with HC.

In addition to recordings of brain activity related to light exposure, our protocol also investigated whether monochromatic light stimulation would affect an ongoing cognitive brain activity by including an auditory working memory task in one of the fMRI sessions. Interestingly, executive brain responses were differentially affected by light wavelength, with blue light associated with higher activations than red light, in LHON patients over the lateral prefrontal cortex (or middle frontal areas) typically involved in higher executive function [63], while such a difference was not detected in HC.

We previously reported only one single study on functional brain MRI responses in a LHON patient [7]. However, the methodology in this case included multimodal stimulation based on auditory elicited visual hallucinations and purely visual checkboard stimulation not evoking any brain activation, and was not aimed at evaluating the brain responses induced by the specific stimulation of mRGCs.

Here, despite the degeneration that affects RGCs and the consequent optic nerve atrophy in LHON patients, it is remarkable that primary visual cortex still reacts to visual stimulation and specifically to blue light stimulation in these patients. These results are in line with others showing that LHON patients were comparable to healthy controls in terms of melatonin suppression, subjective sleepiness and cognitive functions in response to bright light exposure in the evening [11] and therefore suggest that the ability of residual RGCs (and particularly the spared mRGCs) to send signals from retina to the visual cortex is maintained, along with melatonin suppression and other NIF responses such as pupillary reflex [8-11].

It is well-known that the isolation of mRGC contribution to pupil and brain functions in vivo is quite difficult since these cells receive inputs also from the classical photoreceptors, i.e. rods and cones and the spectral sensitivities of these three classes of photoreceptors are in part overlapping (Spitschan et al., 2018) [28]. Thus, methods for silent substitution have been proposed to isolate mRGCs [64] and Spitschan et al., 2018, [28]. Our light stimulation protocol, based on the use of monochromatic blue and red light and on the selective sensitivity of mRGCs to the shorter of the two wavelengths, does not allow to isolate melanopsin contribution per se. In other words, we cannot exclude that rods/cones activity (that remain intact in LHON) is contributing to the effects we measured. However, given the fact that melanopsin is maximally sensitive to blue light and has a sluggish response on one side, and that we have stronger V1 response in LHON with sustained stimuli of blue light on the other side, our results are in line with the inference that the mRGC signal indirectly feeds to the cortex mostly devoted to vision in humans, in addition to their classical role in circadian photoentrainment and other NIF functions $[22,45,45,64]$. The present findings, thus, overall confirm that mRGCs are relatively spared in LHON $[8,10]$.

Moreover, our results are also in line with a role of mRGCs in cortical visual processes [65]. This is in fact highlighted by a direct retinofugal projection of mRGCs to the LGN that, in turn, projects to the primary visual cortex (V1) in mice $[24,32,66]$, rats [67] and non-human primates $[16,21]$. Furthermore, neurophysiological studies in mice suggest that mRGCs can support spatial visual perception (discrimination of very coarse patterns) in animals lacking the classical rod-cone outer retinal system [24]. These studies point to a sustained and scalable response to light stimulation mediated by the dorsal LGN (dLGN) [68] in photopic conditions $[33,69]$. Melanopsin RGCs may drive a generalized increase of dLGN excitability, conveying information about changing background light intensity and increasing the signal/noise for fast visual responses [70]. A retinal circuitry driving changes in RGCs firing as an active response to changes in ambient light to adjust the amount of visual information transmitted to the brain was also previously described [71]. The mRGC projections to LGN may help in the encoding visual images by increasing the thalamic representation of scenes in reference to total radiance [30]. Moreover, knockout mice for melanopsin show an impoverished coding of natural scenes suggesting the influence of mRGCs on the spatial and temporal tuning of dLGN neurons [29].

Melanopsin RGCs also contribute to visual processing through the maintenance of the pupil light reflex and light avoidance behaviour [72]. Finally, a melanopsin system contribution to brightness discrimination has been demonstrated in mice with and without retinal degenerations $[25,28]$. Psychophysical experiments in healthy human subjects have shown a similar role in brightness perception $[25,73]$ and suggested the mRGC capacity to signal slowly changing stimuli of light colour [74]. Further support for the contribution of melanopsin to human vision is provided by recent evidence that spatial patterns that were spectrally indistinguishable for cones but had contrast for melanopsin could be discriminated by healthy human subjects [31]. Likewise, an fMRI study in four healthy subjects demonstrated that high contrast melanopsin-specific light stimuli elicited a response in the primary visual cortex, associated with a brightening of visual perception [64]. The class of mRGCs that more likely play a role in visual forming functions is represented by non-M1 subtypes and in particular by M4 and more recently M5-subtypes [20,75]. In particular, melanopsin photosensitivity contribution of M4 cells output is particularly important for contrast sensitivity functions [76].

Melanopsin-mediated modulation of cognitive brain activity was previously found in sighted subjects over the same lateral prefrontal cortex areas that we isolate in LHON patients [56]. However, we did not find significant differences between executive responses under blue and red light periods in HC as well as no significant difference between groups. The fact that we found a significant difference in the comparison between blue and red light only in LHON patients but not in HC is presumably due to the higher ratio mRGCs/RGCs reported in LHON. The absence of group differences and light condition difference in HC arises in our view from 2 main factors: i) the smaller sample size (previous studies in sighted individual included up to 16 volunteers [40,59], and ii) the reduced magnetic strength ( $1.5 \mathrm{~T} v s .3 \mathrm{~T}$ ), leading to a lower signal and SNR and time required for a brain volume acquisition $(3 \mathrm{~s} v s . \sim 2 \mathrm{~s})$ 
Table 4

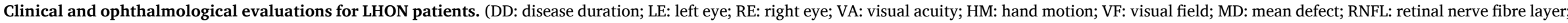
avg = average, T: temporal; S: superior; N: nasal; I: inferior; n.e.: not executed, due to unfeasibility).

\begin{tabular}{|c|c|c|c|c|c|c|c|c|c|c|c|c|c|c|c|c|c|c|c|c|c|}
\hline \multirow[t]{3}{*}{ ID } & \multirow[t]{3}{*}{ Sex } & \multirow{3}{*}{$\begin{array}{l}\text { Age } \\
\text { (yrs) }\end{array}$} & \multirow[t]{3}{*}{ Mutation } & \multirow{3}{*}{$\begin{array}{l}\text { DD } \\
\text { (yrs) }\end{array}$} & \multirow{2}{*}{\multicolumn{2}{|c|}{ VA }} & \multicolumn{5}{|l|}{$\mathrm{VF}$} & \multicolumn{10}{|c|}{ RNFL } \\
\hline & & & & & & & \multirow[t]{2}{*}{ Description } & \multicolumn{2}{|l|}{ LE } & \multicolumn{2}{|l|}{$\mathrm{RE}$} & \multicolumn{5}{|l|}{ LE } & \multicolumn{5}{|l|}{$\mathrm{RE}$} \\
\hline & & & & & LE & $\mathrm{RE}$ & & MD & fovea & MD & fovea & avg & $\mathrm{T}$ & $\mathrm{s}$ & $\mathrm{N}$ & I & avg & $\mathrm{T}$ & $\mathrm{s}$ & $\mathrm{N}$ & I \\
\hline 1 & M & 22 & $\begin{array}{l}11778 / \\
\text { ND4 }\end{array}$ & 5 & $20 / 800$ & $\begin{array}{l}20 / \\
2000\end{array}$ & generalized defect & -33.03 & $\begin{array}{l}\text { not } \\
\text { active }\end{array}$ & -34.1 & $\begin{array}{l}\text { not } \\
\text { active }\end{array}$ & 45 & 31 & 55 & 44 & 51 & 47 & 31 & 59 & 45 & 54 \\
\hline 2 & $\mathrm{M}$ & 27 & $\begin{array}{l}11778 / \\
\text { ND4 }\end{array}$ & 10 & $\begin{array}{l}20 / \\
1250\end{array}$ & $20 / 400$ & $\begin{array}{l}\text { central scotoma right eye; generalized defect } \\
\text { left eye }\end{array}$ & -30.95 & $\begin{array}{l}\text { not } \\
\text { active }\end{array}$ & -16.95 & 18 & 39 & 27 & 5 & 2 & 36 & 39 & 27 & 62 & 33 & 33 \\
\hline 3 & $\mathrm{M}$ & 29 & $\begin{array}{l}11778 / \\
\text { ND4 }\end{array}$ & 4 & $\begin{array}{l}20 / \\
1600\end{array}$ & $\begin{array}{l}20 / \\
2000\end{array}$ & n.e. & n.e. & n.e. & n.e. & n.e. & 44 & 38 & 56 & 46 & 37 & 47 & 32 & 60 & 42 & 54 \\
\hline 4 & M & 29 & $\begin{array}{l}11778 / \\
\text { ND4 }\end{array}$ & 12 & $\begin{array}{l}20 / \\
2000\end{array}$ & $\begin{array}{l}20 / \\
1600\end{array}$ & generalized defect right eye & n.e. & $\begin{array}{l}\text { not } \\
\text { active }\end{array}$ & -34.03 & $\begin{array}{l}\text { not } \\
\text { active }\end{array}$ & 41 & 44 & 35 & 45 & 41 & 32 & 27 & 40 & 34 & 25 \\
\hline 5 & M & 40 & $\begin{array}{l}\text { 11778/ } \\
\text { ND4 }\end{array}$ & 13 & $20 / 320$ & $\begin{array}{l}20 / \\
2000\end{array}$ & generalized defect & -32.96 & n.e. & n.e. & n.e. & 51 & 30 & 73 & 52 & 47 & 56 & 45 & 73 & 43 & 61 \\
\hline 6 & $\mathrm{~F}$ & 54 & $\begin{array}{l}\text { 11778/ } \\
\text { ND4 }\end{array}$ & 24 & $\begin{array}{l}20 / \\
2000\end{array}$ & $20 / 630$ & n.e. & n.e. & n.e. & n.e. & n.e. & 40 & 27 & 54 & 36 & 43 & 41 & 36 & 53 & 33 & 42 \\
\hline 7 & M & 59 & $\begin{array}{l}\text { 11778/ } \\
\text { ND4 }\end{array}$ & 32 & $20 / 500$ & $\begin{array}{l}20 / \\
2000\end{array}$ & generalized defect & -30.99 & $\begin{array}{l}\text { not } \\
\text { active }\end{array}$ & -31.45 & $\begin{array}{l}\text { not } \\
\text { active }\end{array}$ & 50 & 29 & 49 & 60 & 61 & 43 & 27 & 56 & 39 & 51 \\
\hline 8 & M & 34 & $3460 / \mathrm{ND} 1$ & 17 & $20 / 630$ & $20 / 400$ & generalized defect & -31.78 & $\begin{array}{l}\text { not } \\
\text { active }\end{array}$ & -27.14 & $\begin{array}{l}\text { not } \\
\text { active }\end{array}$ & 48 & 40 & 67 & 35 & 52 & 47 & 40 & 54 & 52 & 41 \\
\hline 9 & F & 60 & $3460 / \mathrm{ND} 1$ & 49 & $20 / 320$ & $20 / 200$ & central scotoma bilaterally & -18.05 & 4 & -19.64 & 0 & 53 & 32 & 66 & 46 & 69 & 47 & 29 & 57 & 48 & 54 \\
\hline 10 & M & 39 & 3890/ND1 & 9 & $\begin{array}{l}20 / \\
1250\end{array}$ & $\begin{array}{l}20 / \\
1000\end{array}$ & generalized defect & n.e. & n.e. & -33.42 & $\begin{array}{l}\text { not } \\
\text { active }\end{array}$ & 50 & 38 & 57 & 50 & 57 & 48 & 40 & 63 & 51 & 38 \\
\hline 11 & M & 29 & $\begin{array}{l}14258 / \\
\text { ND6 }\end{array}$ & 13 & $20 / 630$ & $20 / 630$ & generalized defect & -27.33 & $<0$ & -27.72 & $<0$ & 45 & 34 & 54 & 43 & 51 & 48 & 30 & 55 & 59 & 49 \\
\hline 12 & M & 36 & $\begin{array}{l}14484 / \\
\text { ND6 }\end{array}$ & 20 & $\begin{array}{l}20 / \\
1000\end{array}$ & $20 / 125$ & generalized defect & n.e. & n.e. & -32.04 & 20 & 38 & 29 & 43 & 36 & 42 & 37 & 32 & 39 & 39 & 39 \\
\hline
\end{tabular}

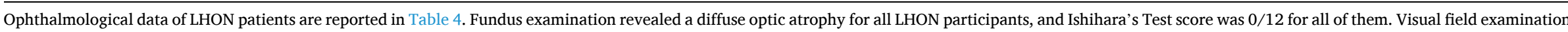

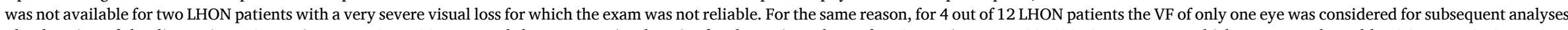

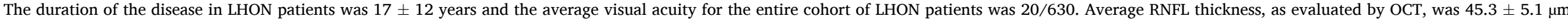
indicating severe optic atrophy. HC subjects had normal ophthalmological exam including OCT and visual acuity was 20/20 in all of them. 
Table 5

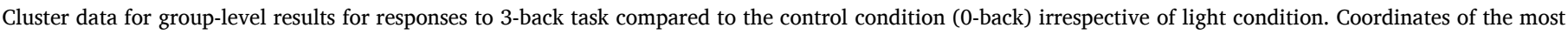

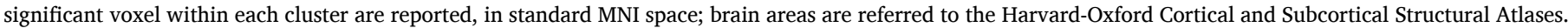

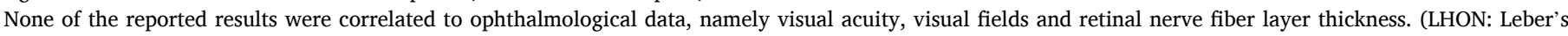
hereditary optic neuropathy; HC: healthy controls; l: left; r: right.)

\begin{tabular}{|c|c|c|c|c|c|c|}
\hline & \multirow[t]{2}{*}{ Volume $\left(\mathrm{mm}^{3}\right)$} & \multirow[t]{2}{*}{ p-value } & \multicolumn{3}{|c|}{ Coordinates (mm) } & \multirow[t]{2}{*}{ Area (side) } \\
\hline & & & $\mathrm{x}$ & $\mathrm{y}$ & $\mathrm{z}$ & \\
\hline \multirow[t]{12}{*}{ HC } & 51016 & $1.00 \mathrm{E}-03$ & -30 & -4 & 56 & Middle frontal gyrus (l) \\
\hline & 11512 & $4.00 \mathrm{E}-03$ & -42 & -42 & 40 & Supramarginal Gyrus (1) \\
\hline & 7408 & $1.40 \mathrm{E}-02$ & -14 & -10 & 18 & Caudate (l) \\
\hline & 1256 & $1.20 \mathrm{E}-02$ & 32 & -68 & -26 & Cerebellum (Right Crus I) \\
\hline & 568 & $3.20 \mathrm{E}-02$ & 32 & 26 & 8 & Frontal Operculum (r) \\
\hline & 464 & $3.30 \mathrm{E}-02$ & 14 & -68 & 60 & Lateral Occipital Cortex (r) \\
\hline & 392 & $4.20 \mathrm{E}-02$ & -64 & -42 & 12 & Supramarginal Gyrus (1) \\
\hline & 376 & 4.10E-02 & -58 & -48 & 34 & Supramarginal Gyrus (1) \\
\hline & 304 & $3.40 \mathrm{E}-02$ & -48 & -44 & 0 & Middle Temporal Gyrus (l) \\
\hline & 168 & $3.90 \mathrm{E}-02$ & 30 & -70 & -48 & Cerebellum (Right VIIb) \\
\hline & 128 & 4.60E-02 & 8 & -78 & -18 & Lingual Gyrus (1) \\
\hline & 80 & 4.70E-02 & 48 & -34 & 48 & Supramarginal Gyrus (r) \\
\hline \multirow[t]{8}{*}{ LHON } & 71336 & $3.00 \mathrm{E}-03$ & 42 & 0 & 34 & Precentral Gyrus (r) \\
\hline & 8168 & $9.00 \mathrm{E}-03$ & 34 & -66 & 46 & Lateral Occipital Cortex (r) \\
\hline & 7504 & $6.00 \mathrm{E}-03$ & -38 & -52 & 38 & Angular Gyrus (l) \\
\hline & 5936 & $5.00 \mathrm{E}-03$ & 36 & 26 & 0 & Frontal Orbital Cortex (r) \\
\hline & 344 & $3.00 \mathrm{E}-02$ & 10 & -82 & -26 & Occipital Fusiform Gyrus (r) \\
\hline & 176 & 4.90E-02 & -32 & 52 & 6 & Frontal Pole (l) \\
\hline & 112 & 4.80E-02 & -26 & 66 & 8 & Frontal Pole (1) \\
\hline & 80 & $3.80 \mathrm{E}-02$ & 30 & -66 & -28 & Cerebellum (Right Crus I) \\
\hline LHON > HC & no significant voxels & & & & & \\
\hline LHON < HC & no significant voxels & & & & & \\
\hline
\end{tabular}

$[45,56,59]$. We further emphasize that, despite all these limitations, we were able to isolate a light condition impact while performing a cognitive task in part of our sample (and across both groups without cognitive tasks - cf. above). The fact that differential impact of light wavelength on ongoing brain activity was most evident in the LHON group gives further support to an important role of mRGCs in modulating ongoing cognitive activity. Aside from a maximal sensitivity to blue light compared to other wavelengths $[45,56]$ a similar result was previously suggested in a study in sighted healthy young volunteers in which prior light history was manipulated to affect mRGC sensitivity [40], and in 3 totally blind subjects due to outer retinal disorders, with no conscious vision but retained NIF photoreception [45].

Finally, despite brain response modulations by blue light in LHON, we did not find an effect of light on behavioural performances. This is not unexpected, given that, as in previous studies in healthy subjects [56], we were careful at keeping task blocks short to avoid any behavioural effects that could contaminate the results. Both patients and controls are cognitively intact, and our light stimulation scheme included short exposures to light ( $<1 \mathrm{~min}$ ), which differs markedly from what is described for other investigation meant to trigger improvements in cognitive performance, i.e. hour long exposures, sometimes repeated over a week [37].

To our knowledge, the present study is the first to explore and demonstrate the visually-evoked brain activity in LHON, an inherited optic neuropathy that is characterized by a selective relative sparing of the mRGC system. Even if melanopsin contribution was not uniquely isolated, these results are suggestive of a possible role of mRGCs in modulating the occipital cortex response in LHON patients, even when the brain is not engaged in a cognitive challenge, and the prefrontal cortex when engaged in a cognitive process. This early experiment will hopefully pave the way to further studies, more selectively stimulating melanopsin in LHON, as it provides an unparalleled paradigm of study given RGCs selective degeneration, and to the opening of potential windows for therapy in these patients.

\section{CRediT authorship contribution statement}

Stefania Evangelisti: Conceptualization, Investigation, Formal analysis, Software, Writing - original draft. Chiara La Morgia: Conceptualization, Investigation, Resources, Writing - original draft. Claudia Testa: Conceptualization, Investigation, Formal analysis, Writing - original draft. David N. Manners: Investigation. Leonardo Brizi: Investigation. Claudio Bianchini: Investigation. Michele Carbonelli: Investigation. Piero Barboni: Investigation. Alfredo A. Sadun: Conceptualization. Caterina Tonon: Conceptualization. Valerio Care1li: Conceptualization, Resources, Supervision. Gilles Vandewalle: Conceptualization, Supervision. Raffaele Lodi: Conceptualization, Resources, Supervision.

\section{Acknowledgments}

We thank Fondazione del Monte di Bologna e Ravenna for the financial support. GV is supported by the Fonds National de la Recherche Scientifique (FNRS-Belgium). These funding agencies had no role in study design, in the collection, analysis and interpretation of data, in the writing of the report and in the decision to submit the article for publication.

\section{Declarations of Competing Interest}

Dr. La Morgia reports personal fees from Santhera Pharmaceuticals, Regulatory Pharmanet and Chiesi Farmaceutici, grants from Italian Ministry of Health Grant- GR-2013-02358026 "Melanopsin retinal ganglion cells and circadian rhythms: function and dysfunction in Alzheimer's disease and aging" (PI), grants from Italian Ministry of Health Grant-GR-2016-02361449 "Italian Project on Hereditary Optic Neropathies (IPHON): from genetic basis to therapy" (Co-PI), outside the submitted work.

Dr. Carbonelli reports personal fees from Santhera Pharmaceuticals, outside the submitted work.

Dr. Barboni reports personal fees from Santhera Pharmaceuticals, personal fees from Omikron pharma, outside the submitted work.

Dr. Sadun reports grants from Stealth Biopeptides - LHON Clinical Trial, grants from GenSight - LHON Clinical Trial, outside the submitted work.

Prof. Carelli reports personal fees from Santhera Pharmaceuticals, 
grants from Stealth BioTherapeutics, personal fees from GenSight Biologics, grants from Italian Ministry of Health, RF-2018-12366703, "REtinal ganglion cells and ORganoids from Inherited Optic Neuropathies: light on pathogenesis to fight blindness (REORION Project)" (PI), grants from Italian Ministry of University and Research, 20172T2MHH, "Keeping mitochondrial DNA in shape in health and disease: cracking the elusive relationship between the fusion protein OPA1 and mtDNA maintenance in membrane-anchored nucleoids" (PI), outside the submitted work.

Dr. Evangelisti, Dr. Testa, Dr. Bianchini, Dr. Manners, Dr. Brizi, Prof. Tonon, Dr. Vandewalle and Prof. Lodi report no disclosures.

\section{References}

[1] B. Mascialino, M. Leinonen, T. Meier, Meta-analysis of the prevalence of Leber hereditary optic neuropathy mtDNA mutations in Europe, Eur. J. Ophthalmol. 22 (3) (2012) 461-465, https://doi.org/10.5301/ejo.5000055.

[2] V. Carelli, F.N. Ross-Cisneros, A.A. Sadun, Mitochondrial dysfunction as a cause of optic neuropathies, Prog. Retinal Eye Res. 23 (1) (2004) 53-89, https://doi.org/ 10.1016/j.preteyeres.2003.10.003.

[3] G. Rizzo, K.R. Tozer, C. Tonon, D. Manners, C. Testa, E. Malucelli, M.L. Valentino, C. La Morgia, P. Barboni, R.S. Randhawa, F.N. Ross-Cisneros, A.A. Sadun, V. Carelli, R. Lodi, F. Paul, Secondary post-geniculate involvement in leber's hereditary optic neuropathy, PLoS One 7 (11) (2012) e50230, https://doi.org/ 10.1371/journal.pone.0050230.

[4] D.N. Manners, G. Rizzo, C. La Morgia, C. Tonon, C. Testa, P. Barboni, E. Malucelli, M.L. Valentino, L. Caporali, D. Strobbe, V. Carelli, R. Lodi, Diffusion tensor imaging mapping of brain white matter pathology in mitochondrial optic neuropathies, Am. J. Neuroradiol. 36 (7) (2015) 1259-1265, https://doi.org/10.3174/ajnr.A4272.

[5] V. Barcella, M.A. Rocca, S. Bianchi-Marzoli, J. Milesi, L. Melzi, A. Falini, L. Pierro M. Filippi, Evidence for retrochiasmatic tissue loss in Leber's hereditary optic neuropathy, Hum. Brain Mapp. 31 (12) (2010) 1900-1906, https://doi.org/ 10.1002/hbm.20985.

[6] M.A. Rocca, P. Valsasina, E. Pagani, S. Bianchi-Marzoli, J. Milesi, A. Falini, G. Comi, M. Filippi, Y.i. Wang, Extra-visual functional and structural connection abnormalities in leber's hereditary optic neuropathy, PLoS One 6 (2) (2011) e17081, https://doi.org/10.1371/journal.pone.0017081.t002.

[7] V. Vacchiano, C. Tonon, M. Mitolo, S. Evangelisti, M. Carbonelli, R. Liguori, R. Lodi, V. Carelli, C. La Morgia, Functional MRI study in a case of Charles Bonnet syndrome related to LHON, BMC Neurol. 19 (1) (2019) 350, https://doi.org/ 10.1186/s12883-019-1579-9.

[8] C. La Morgia, F.N. Ross-Cisneros, A.A. Sadun, J. Hannibal, A. Munarini, V. Mantovani, P. Barboni, G. Cantalupo, K.R. Tozer, E. Sancisi, S.R. Salomao, M. N. Moraes, M.N. Moraes-Filho, S. Heegaard, D. Milea, P. Kjer, P. Montagna, V. Carelli, Melanopsin retinal ganglion cells are resistant to neurodegeneration in mitochondrial optic neuropathies, Brain 133 (8) (2010) 2426-2438, https://doi. org/10.1093/brain/awq155.

[9] A. Kawasaki, K. Herbst, B. Sander, D. Milea, Selective wavelength pupillometry in Leber hereditary optic neuropathy, Clin. Exp. Ophthalmol. 38 (3) (2010) 322-324, https://doi.org/10.1111/j.1442-9071.2010.02212.x.

[10] A.L. Moura, B.V. Nagy, C. La Morgia, P. Barboni, A.G. Oliveira, S.R. Salomão, A. Berezovsky, M.N. de Moraes-Filho, C.F. Chicani, R. Belfort Jr, V. Carelli, A. A. Sadun, D.C. Hood, D.F. Ventura, The pupil light reflex in Leber's hereditary optic neuropathy: evidence for preservation of melanopsin-expressing retinal ganglion cells, Invest. Ophthalmol. Vis. Sci. 54 (7) (2013) 4471-4477, https://doi org/10.1167/iovs.12-11137.

[11] M. Münch, L. Léon, S. Collomb, A. Kawasaki, Comparison of acute non-visual bright light responses in patients with optic nerve disease, glaucoma and healthy controls, Sci. Rep. 19 (5) (2015) 15185, https://doi.org/10.1038/srep15185.

[12] I. Příhodová, J. Nepožitek, S. Kelifová, S. Dostálová, D. Kemlink, K. Šonka, M. Tesařová, T. Honzík, H. Kolářová, Subjective and polysomnographic evaluation of sleep in mitochondrial optic neuropathies, J. Sleep Res. (2020) e13051, https:// doi.org/10.1111/jsr.13051.

[13] D.M. Berson, F.A. Dunn, M. Takao, Phototransduction by retinal ganglion cells that set the circadian clock, Science (New York, N.Y.) 295 (5557) (2002) 1070-1073, https://doi.org/10.1126/science.1067262.

[14] S. Hattar, H.W. Liao, M. Takao, D.M. Berson, K.W. Yau, Melanopsin-containing retinal ganglion cells: architecture, projections, and intrinsic photosensitivity, Science 295 (5557) (2002) 1065-1070, https://doi.org/10.1126/science.1069609.

[15] J. Hannibal, L. Kankipati, C.E. Strang, B.B. Peterson, D. Dacey, P.D. Gamlin, Central projections of intrinsically photosensitive retinal ganglion cells in the macaque monkey: central projections of intrinsically photosensitive RGCs in macaque, J. Comp. Neurol. 522 (10) (2014), https://doi.org/10.1002/cne.23588. Spc1-Spc1.

[16] J. Hannibal, A.T. Christiansen, S. Heegaard, J. Fahrenkrug, J.F. Kiilgaard, Melanopsin expressing human retinal ganglion cells: subtypes, distribution, and intraretinal connectivity, J. Comp. Neurol. 525 (8) (2017) 1934-1961, https://doi. $\operatorname{org} / 10.1002 / \mathrm{cne} .24181$

[17] J.J. Gooley, I. Ho Mien, M.A. St. Hilaire, S.-C. Yeo, E.- C.-P. Chua, E. van Reen, C. J. Hanley, J.T. Hull, C.A. Czeisler, S.W. Lockley, Melanopsin and rod-cone photoreceptors play different roles in mediating pupillary light responses during exposure to continuous light in humans, J. Neurosci. 32 (41) (2012) 14242-14253, https://doi.org/10.1523/JNEUROSCI.1321-12.2012.

[18] A. Sand, T.M. Schmidt, P. Kofuji, Diverse types of ganglion cell photoreceptors in the mammalian retina, Prog. Retinal Eye Res. 31 (4) (2012) 287-302, https://doi. org/10.1016/j.preteyeres.2012.03.003.

[19] G. Gaggioni, P. Maquet, C. Schmidt, D.J. Dijk, G. Vandewalle, Neuroimaging, cognition, light and circadian rhythms, Front. Syst. Neurosci. 8 (2014) 126, https://doi.org/10.3389/fnsys.2014.00126.

[20] M.L. Aranda, T.M. Schmidt, Diversity of intrinsically photosensitive retinal ganglion cells: circuits and functions, Cell. Mol. Life Sci. (2020).

[21] D.M. Dacey, H.-W. Liao, B.B. Peterson, F.R. Robinson, V.C. Smith, J. Pokorny, K.W. Yau, P.D. Gamlin, Melanopsin-expressing ganglion cells in primate retina signal colour and irradiance and project to the LGN, Nature 433 (7027) (2005) 749-754, https://doi.org/10.1038/nature03387.

[22] M.W. Hankins, S.N. Peirson, R.G. Foster, Melanopsin: an exciting photopigment, Trends Neurosci. 31 (1) (2008) 27-36, https://doi.org/10.1016/j tins.2007.11.002

[23] L.S. Mure, F. Vinberg, A. Hanneken, S. Panda, Functional diversity of human intrinsically photosensitive retinal ganglion cells, Science 366 (6470) (2019) 1251-1255, https://doi.org/10.1126/science:aaz0898.

[24] J.L. Ecker, O.N. Dumitrescu, K.Y. Wong, N.M. Alam, S.-K. Chen, T. LeGates, J. M. Renna, G.T. Prusky, D.M. Berson, S. Hattar, Melanopsin-expressing retinal ganglion-cell photoreceptors: cellular diversity and role in pattern vision, Neuron 67 (1) (2010) 49-60, https://doi.org/10.1016/j.neuron.2010.05.023.

[25] T. Brown, S.-I. Tsujimura, A. Allen, J. Wynne, R. Bedford, G. Vickery, A. Vugler, R. Lucas, Melanopsin-based brightness discrimination in mice and humans, Curr. Biol. 22 (12) (2012) 1134-1141, https://doi.org/10.1016/j.cub.2012.04.039.

[26] C.A. Procyk, C.G. Eleftheriou, R. Storchi, A.E. Allen, N. Milosavljevic, T.M. Brown, R.J. Lucas, Spatial receptive fields in the retina and dorsal lateral geniculate nucleus of mice lacking rods and cones, J. Neurophysiol. 114 (2) (2015) 1321-1330, https://doi.org/10.1152/jn.00368.2015.

[27] N. Milosavljevic, A.E. Allen, J. Cehajic-Kapetanovic, R.J. Lucas, Chemogenetic activation of ipRGCs drives changes in dark-adapted (Scotopic) electroretinogram, Invest. Ophthalmol. Vis. Sci. 57 (14) (2016) 6305-6312, https://doi.org/10.1167/ iovs.16-20448.

[28] R.J. Lucas, A.E. Allen, N. Milosavljevic, R. Storchi, T. Woelders, Can we see with melanopsin? Annu. Rev. Vis. Sci. 6 (1) (2020) 453-468, https://doi.org/10.1146/ annurev-vision-030320-041239.

[29] A. Allen, R. Storchi, F. Martial, R. Petersen, M. Montemurro, T. Brown, R. Lucas, Melanopsin-driven light adaptation in mouse vision, Curr. Biol. 24 (21) (2014) 2481-2490, https://doi.org/10.1016/j.cub.2014.09.015.

[30] A.E. Allen, R. Storchi, F.P. Martial, R.A. Bedford, R.J. Lucas, Melanopsin contributions to the representation of images in the early visual system, Curr. Biol. 27 (11) (2017) 1623-1632.e4, https://doi.org/10.1016/j.cub.2017.04.046.

[31] A.E. Allen, F.P. Martial, R.J. Lucas, Form vision from melanopsin in humans, Nat. Commun. 10 (1) (2019) 2274, https://doi.org/10.1038/s41467-019-10113-3.

[32] S. Hattar, M. Kumar, A. Park, P. Tong, J. Tung, K.-W. Yau, D.M. Berson, Central projections of melanopsin-expressing retinal ganglion cells in the mouse, J. Comp. Neurol. 497 (3) (2006) 326-349, https://doi.org/10.1002/cne.20970.

[33] K.E. Davis, C.G. Eleftheriou, A.E. Allen, C.A. Procyk, R.J. Lucas, S.G. Solomon, Melanopsin-derived visual responses under light adapted conditions in the mouse dLGN, PLoS One 10 (3) (2015) e0123424, https://doi.org/10.1371/journal. pone.0123424.g007.

[34] C.A. Procyk, A.E. Allen, F.P. Martial, R.J. Lucas, Visual responses in the dorsa lateral geniculate nucleus at early stages of retinal degeneration in $r d 1$ PDE6 $\beta$ mice, J. Neurophysiol. 122 (4) (2019) 1753-1764, https://doi.org/10.1152/ jn.00231.2019.

[35] R. Storchi, R.A. Bedford, F.P. Martial, A.E. Allen, J. Wynne, M.A. Montemurro, R. S. Petersen, R.J. Lucas, Modulation of fast narrowband oscillations in the mouse retina and dLGN according to background light intensity, Neuron 93 (2) (2017) 299-307, https://doi.org/10.1016/j.neuron.2016.12.027. PMID: 28103478.

[36] G. Vandewalle, P. Maquet, D.-J. Dijk, Light as a modulator of cognitive brain function, Trends Cognit. Sci. 13 (10) (2009) 429-438, https://doi.org/10.1016/j tics.2009.07.004.

[37] M. Mitolo, C. Tonon, C. La Morgia, C. Testa, V. Carelli, R. Lodi, Effects of light treatment on sleep, cognition, mood, and behavior in Alzheimer's disease: a systematic review, Dement. Geriatr. Cogn. Disord. 46 (5-6) (2019) 371-384, https://doi.org/10.1159/000494921.

[38] S.-M. Hung, D. Milea, A.V. Rukmini, R.P. Najjar, J.H. Tan, F. Viénot, M. Dubail, S.L. C. Tow, T. Aung, J.J. Gooley, P.-J. Hsieh, Cerebral neural correlates of differential melanopic photic stimulation in humans, NeuroImage 146 (2017) 763-769, https://doi.org/10.1016/j.neuroimage.2016.09.061.

[39] E.M. McGlashan, G.R. Poudel, P. Vidafar, S.P.A. Drummond, S.W. Cain, Imaging individual differences in the response of the human suprachiasmatic area to light, Front. Neurol. 9 (2018), https://doi.org/10.3389/fneur.2018.01022.s001.

[40] S.L. Chellappa, J.Q.M. Ly, C. Meyer, E. Balteau, C. Degueldre, A. Luxen, C. Phillips, H.M. Cooper, G. Vandewalle, Photic memory for executive brain responses, Proc. Natl. Acad. Sci. 111 (16) (2014) 6087-6091, https://doi.org/10.1073/ pnas.1320005111.

[41] A.D. Güler, J.L. Ecker, G.S. Lall, S. Haq, C.M. Altimus, H.-W. Liao, A.R. Barnard, H. Cahill, T.C. Badea, H. Zhao, M.W. Hankins, D.M. Berson, R.J. Lucas, K.-W. Yau, S. Hattar, Melanopsin cells are the principal conduits for rod-cone input to nonimage-forming vision, Nature 453 (7191) (2008) 102-105, https://doi.org/ 10.1038/nature06829.

[42] C.A. Czeisler, T.L. Shanahan, E.B. Klerman, H. Martens, D.J. Brotman, J.S. Emens, T. Klein, J.F. Rizzo 3rd, Suppression of melatonin secretion in some blind patients 
by exposure to bright light, New Engl. J. Med. 332 (1) (1995) 6-11, https://doi. org/10.1056/NEJM199501053320102.

[43] F.H. Zaidi, J.T. Hull, S.N. Peirson, K. Wulff, D. Aeschbach, J.J. Gooley, G. C. Brainard, K. Gregory-Evans, J.F. Rizzo III, C.A. Czeisler, R.G. Foster, M. J. Moseley, S.W. Lockley, Short-wavelength light sensitivity of circadian, pupillary, and visual awareness in humans lacking an outer retina, Curr. Biol. 17 (24) (2007) 2122-2128, https://doi.org/10.1016/j.cub.2007.11.034.

[44] J.T. Hull, C.A. Czeisler, S.W. Lockley, Suppression of melatonin secretion in totally visually blind people by ocular exposure to white light, Ophthalmology 125 (8) (2018) 1160-1171, https://doi.org/10.1016/j.ophtha.2018.01.036.

[45] G. Vandewalle, O. Collignon, J.T. Hull, V. Daneault, G. Albouy, F. Lepore, C. Phillips, J. Doyon, C.A. Czeisler, M. Dumont, S.W. Lockley, J. Carrier, Blue light stimulates cognitive brain activity in visually blind individuals, J. Cognit. Neurosci. 25 (12) (2013) 2072-2085, https://doi.org/10.1162/jocn_a_00450.

[46] G. Vandewalle, M.J. van Ackeren, V. Daneault, J.T. Hull, G. Albouy, F. Lepore, J. Doyon, C.A. Czeisler, M. Dumont, J. Carrier, S.W. Lockley, O. Collignon, Light modulates oscillatory alpha activity in the occipital cortex of totally visually blind individuals with intact non-image-forming photoreception, Sci. Rep. 8 (1) (2018) 16968, https://doi.org/10.1038/s41598-018-35400-9.

[47] J.A. Horne, O. Ostberg, A self-assessment questionnaire to determine morningnesseveningness in human circadian rhythms, Int. J. Chronobiol. 4 (2) (1976) 97-110.

[48] D.J. Buysse, C.F. Reynolds III, T.H. Monk, S.R. Berman, D.J. Kupfer, The Pittsburgh sleep quality index: a new instrument for psychiatric practice and research, Psychiatry Res. 28 (2) (1989) 193-213, https://doi.org/10.1016/0165-1781(89) 90047-4.

[49] N.C. Netzer, R.A. Stoohs, C.M. Netzer, K. Clark, K.P. Strohl, Using the Berlin Questionnaire to identify patients at risk for the sleep apnea syndrome, Ann. Intern. Med. 131 (7) (1999) 485-491, https://doi.org/10.7326/0003-4819-131-7 199910050-00002.

[50] L. Vignatelli, G. Plazzi, A. Barbato, L. Ferini-Strambi, R. Manni, F. Pompei, R. D'Alessandro, GINSEN (Gruppo Italiano Narcolessia Studio Epidemiologico Nazionale, Italian version of the Epworth sleepiness scale: external validity, Neurol. Sci. 23 (6) (2003) 295-300, https://doi.org/10.1007/s100720300004.

[51] A.T. Beck, N. Epstein, G. Brown, R.A. Steer, An inventory for measuring clinical anxiety: Psychometric properties. J. Consult. Clin. Psychol. 56 (6) (1988) 893-897, https://doi.org/10.1037//0022-006X.56.6.893.

[52] A.T. Beck, C.H. Ward, M. Mendelson, J. Mock, J. Erbaugh, An inventory for measuring depression, Arch. Gen. Psychiatry 4 (1961) 561-571, https://doi.org/ 10.1001/archpsyc.1961.01710120031004.

[53] C. Meyer, V. Muto, M. Jaspar, C. Kussé, E. Lambot, S.L. Chellappa, C. Degueldre, E. Balteau, A. Luxen, B. Middleton, S.N. Archer, F. Collette, D.-J. Dijk, C. Phillips, P. Maquet, G. Vandewalle, Seasonality in human cognitive brain responses, Proc. Natl. Acad. Sci. U.S.A. 113 (11) (2016) 3066-3071, https://doi.org/10.1073/ pnas. 1518129113.

[54] CIE System for Metrology of Optical Radiation for ipRGC-Influenced Responses to Light: CIE S 026/E:2018; DOI: 10.25039/S026.2018.

[55] International Commission on Non-Ionizing Radiation Protection. ICNIRP (2013) guidelines on limits of exposure to incoherent visible and infrared radiation. Health Phys,105(1):74-96, 2013.

[56] G. Vandewalle, C. Schmidt, G. Albouy, V. Sterpenich, A. Darsaud, G. Rauchs, P. Y. Berken, E. Balteau, C. Degueldre, A. Luxen, P. Maquet, D.-J. Dijk, S. He, Brain responses to violet, blue, and green monochromatic light exposures in humans: prominent role of blue light and the brainstem, PLoS One 2 (11) (2007) e1247, https://doi.org/10.1371/journal.pone.0001247.s008.

[57] J.D. Cohen, W.M. Perlstein, T.S. Braver, L.E. Nystrom, D.C. Noll, J. Jonides, E. E. Smith, Temporal dynamics of brain activation during a working memory task, Nature 386 (6625) (1997) 604-608, https://doi.org/10.1038/386604a0.

[58] F. Collette, M. Hogge, E. Salmon, M. Van der Linden, Exploration of the neura substrates of executive functioning by functional neuroimaging, Neuroscience 139 (1) (2006) 209-221, https://doi.org/10.1016/j.neuroscience:2005.05.035.

[59] G. Vandewalle, M. Hébert, C. Beaulieu, L. Richard, V. Daneault, M.-L. Garon, J. Leblanc, D. Grandjean, P. Maquet, S. Schwartz, M. Dumont, J. Doyon, J. Carrier, Abnormal hypothalamic response to light in seasonal affective disorder, Biol. Psychiatry 70 (10) (2011) 954-961, https://doi.org/10.1016/j. biopsych.2011.06.022.
[60] S.B. Eickhoff, K.E. Stephan, H. Mohlberg, C. Grefkes, G.R. Fink, K. Amunts, K. Zilles, A new SPM toolbox for combining probabilistic cytoarchitectonic maps and functional imaging data, NeuroImage 25 (4) (2005) 1325-1335, https://doi. org/10.1016/j.neuroimage.2004.12.034.

[61] H. Wang, W. He, J. Wu, J. Zhang, Z. Jin, L. Li, A coordinate-based meta-analysis of the n-back working memory paradigm using activation likelihood estimation, Brain Cogn. 132 (2019) 1-12, https://doi.org/10.1016/j.bandc.2019.01.002.

[62] P. Barboni, M. Carbonelli, G. Savini, B. Foscarini, V. Parisi, M.L. Valentino, A. Carta, A.D. Negri, F. Sadun, M. Zeviani, A.A. Sadun, S. Schimpf, B. Wissinger, V. Carelli, OPA1 mutations associated with dominant optic atrophy influence optic nerve head size, Ophthalmology 117 (8) (2010) 1547-1553, https://doi.org/ 10.1016/j.ophtha.2009.12.042.

[63] T.M. Otero, L.A. Barker, The frontal lobes and executive functioning, in: S. Goldstein, J.A. Naglieri (Eds.), Handbook of Executive Functioning, Springer, New York, NY, 2014.

[64] M. Spitschan, A.S. Bock, J. Ryan, G. Frazzetta, D.H. Brainard, G.K. Aguirre, The human visual cortex response to melanopsin-directed stimulation is accompanied by a distinct perceptual experience, Proc. Natl. Acad. Sci. U.S.A. 114 (46) (2017) 12291-12296, https://doi.org/10.1073/pnas.1711522114.

[65] T. Sonoda, T.M. Schmidt, Re-evaluating the role of intrinsically photosensitive retinal ganglion cells: new roles in image-forming functions, Integr. Comp. Biol. 56 (5) (2016) 834-841, https://doi.org/10.1093/icb/icw066.

[66] M. Hatori, H. Le, C. Vollmers, S.R. Keding, N. Tanaka, C. Schmedt, T. Jegla, S. Panda, M. Hendricks, Inducible ablation of melanopsin-expressing retinal ganglion cells reveals their central role in non-image forming visual responses, PLoS One 3 (6) (2008) e2451, https://doi.org/10.1371/journal.pone.0002451. g006.

[67] J.L. Langel, L. Smale, G. Esquiva, J. Hannibal, Central melanopsin projections in the diurnal rodent, Arvicanthis niloticus, Front. Neuroanatomy 9 (2015) 93, https://doi.org/10.3389/fnana.2015.00093.

[68] T.M. Brown, C. Gias, M. Hatori, S.R. Keding, M. Semo, P.J. Coffey, J. Gigg, H. D. Piggins, S. Panda, R.J. Lucas, F. Rieke, Melanopsin contributions to irradiance coding in the thalamo-cortical visual system, PLoS Biol. 8 (12) (2010) e1000558, https://doi.org/10.1371/journal.pbio.1000558.s009.

[69] J.W. Mouland, A.R. Stinchcombe, D.B. Forger, T.M. Brown, R.J. Lucas, Responses to spatial contrast in the mouse Suprachiasmatic nuclei, Curr. Biol. 27 (11) (2017) 1633-1640.e3, https://doi.org/10.1016/j.cub.2017.04.039.

[70] R. Storchi, N. Milosavljevic, C.G. Eleftheriou, F.P. Martial, P. Orlowska-Feuer, R. A. Bedford, T.M. Brown, M.A. Montemurro, R.S. Petersen, R.J. Lucas, Melanopsindriven increases in maintained activity enhance thalamic visual response reliability across a simulated dawn, Proc. Natl. Acad. Sci. U.S.A. 112 (42) (2015) E5734-E5743, https://doi.org/10.1073/pnas.1505274112.

[71] N. Milosavljevic, R. Storchi, C.G. Eleftheriou, A. Colins, R.S. Petersen, R.J. Lucas, Photoreceptive retinal ganglion cells control the information rate of the optic nerve, Proc. Natl. Acad. Sci. U.S.A. 115 (50) (2018) E11817-E11826, https://doi. org/10.1073/pnas.1810701115.

[72] J. Johnson, V. Wu, M. Donovan, S. Majumdar, R.C. Renteria, T. Porco, R.N. Van Gelder, D.R. Copenhagen, Melanopsin-dependent light avoidance in neonatal mice, Proc. Natl. Acad. Sci. 107 (40) (2010) 17374-17378, https://doi.org/10.1073/ pnas.1008533107.

[73] A.J. Zele, P. Adhikari, B. Feigl, D. Cao, Cone and melanopsin contributions to human brightness estimation, J. Opt. Soc. Am. A 35 (4) (2018) B19-B25, https:// doi.org/10.1364/JOSAA.35.000B19.

[74] A.J. Zele, B. Feigl, P. Adhikari, M.L. Maynard, D. Cao, Melanopsin photoreception contributes to human visual detection, temporal and colour processing, Sci. Rep. 8 (1) (2018) 3842, https://doi.org/10.1038/s41598-018-22197-w.

[75] T. Schmidt, N. Alam, S. Chen, P. Kofuji, W. Li, G. Prusky, S. Hattar, A role for melanopsin in alpha retinal ganglion cells and contrast detection, Neuron 82 (4) (2014) 781-788, https://doi.org/10.1016/j.neuron.2014.03.022.

[76] M.M. Schroeder, K.R. Harrison, E.R. Jaeckel, H.N. Berger, X. Zhao, M.P. Flannery, E.C. St Pierre, N. Pateqi, A. Jachimska, A.P. Chervenak, K.Y. Wong, The roles of rods, cones, and melanopsin in photoresponses of M4 intrinsically photosensitive retinal ganglion cells (ipRGCs) and optokinetic visual behavior, Front. Cell. Neurosci. 12 (2018) 203, https://doi.org/10.3389/fncel.2018.00203. 